Review

\title{
Vertical Transistors Based on 2D Materials: Status and Prospects
}

\author{
Filippo Giannazzo ${ }^{1, *(1)}$, Giuseppe Greco ${ }^{1}$, Fabrizio Roccaforte ${ }^{1 \text { (I) }}$ and Sushant S. Sonde ${ }^{2,3, * \text { (i) }}$ \\ 1 Consiglio Nazionale delle Ricerche-Institute for Microelectronics and Microsystems (CNR-IMM), \\ Strada VIII, 5 I-95121 Catania, Italy; giuseppe.greco@imm.cnr.it (G.G.); fabrizio.roccaforte@imm.cnr.it (F.R.) \\ 2 Institute for Molecular Engineering, The University of Chicago, Eckhardt Research Center, \\ 5640 South Ellis Avenue, Chicago, IL 60637, USA \\ 3 Center for Nanoscale Materials, Argonne National Laboratory, 9700 Cass Ave, Lemont, IL 60439, USA \\ * Correspondence: filippo.giannazzo@imm.cnr.it (F.G.); sushantsonde@uchicago.edu (S.S.S.)
}

Received: 15 December 2017; Accepted: 29 January 2018; Published: 31 January 2018

\begin{abstract}
Two-dimensional (2D) materials, such as graphene (Gr), transition metal dichalcogenides (TMDs) and hexagonal boron nitride (h-BN), offer interesting opportunities for the implementation of vertical transistors for digital and high-frequency electronics. This paper reviews recent developments in this field, presenting the main vertical device architectures based on 2D/2D or 2D/3D material heterostructures proposed so far. For each of them, the working principles and the targeted application field are discussed. In particular, tunneling field effect transistors (TFETs) for beyond-CMOS low power digital applications are presented, including resonant tunneling transistors based on Gr/h-BN/Gr stacks and band-to-band tunneling transistors based on heterojunctions of different semiconductor layered materials. Furthermore, recent experimental work on the implementation of the hot electron transistor (HET) with the Gr base is reviewed, due to the predicted potential of this device for ultra-high frequency operation in the $\mathrm{THz}$ range. Finally, the material sciences issues and the open challenges for the realization of 2D material-based vertical transistors at a large scale for future industrial applications are discussed.
\end{abstract}

Keywords: graphene; 2D materials; van der Waals heterostructures; vertical field effect transistors; hot electron transistors

\section{Introduction}

In 2004, the pioneering works on the field effect in atomically thin carbon films [1], from then on named graphene (Gr), gave birth to an entirely new research branch of solid-state electronics, focused on the use of two-dimensional (2D) materials and their heterostructures for electronics/optoelectronics devices with unconventional or improved performances compared to traditional semiconductor devices. Due to its excellent carrier mobility (up to $\sim 10^{5} \mathrm{~cm}^{2} \mathrm{~V}^{-1} \mathrm{~s}^{-1}$ ) [2,3] and micrometer electron mean free path [4-7], Gr has been considered since the first studies as the channel material for fast field effect transistors (FETs) [8]. Essentially, the Gr field effect transistor (GFET) resembles the classical metal-oxide-semiconductor FET architecture, where lateral transport in the channel is modulated by a gate electrode separated from $\mathrm{Gr}$ by a thin insulator. As a matter of fact, the lack of a bandgap in the electronics band structure of Gr results in a poor ON/OFF current ratio in GFETs, making them unsuitable for digital (logic) or switching applications [9]. On the other hand, GFETs can be of interest for radio frequency (RF) applications, where fast current modulation of the device operated in the on-state is required and switch-off is not necessarily needed $[9,10]$. To date, RF GFETs allowing current amplification at very high frequencies $(>400 \mathrm{GHz}$ ) have been demonstrated [11]. However, the same devices suffer from limited performances in terms of voltage and power amplification, mainly due to the high output conductance resulting from the lack of a bandgap. On the other hand, the peculiar 
symmetric ambipolar conduction of GFETs has been exploited to demonstrate novel device concepts, such as the RF mixer [12].

To overcome the $\mathrm{Gr}$ fundamental limitations arising from the missing bandgap both in digital and RF electronics, new solutions have been explored inside the wide family of 2D materials. In particular, two routes have been followed by scientists working in this field.

The first route was replacing $\mathrm{Gr}$ as the channel material in lateral FETs with semiconducting 2D materials, such as some members of the transition metal dichalcogenides (TMDs) family $\left(\mathrm{MoS}_{2}, \mathrm{WS}_{2}\right.$, $\mathrm{MoSe}_{2}, \mathrm{WSe}_{2}$ ) [13] or phosphorene (a 2D lattice composed of phosphorus atoms) [14]. The second route has been to introduce novel device architectures based on van der Waals (vdW) heterostructures obtained by the stacking of 2D materials (such as Gr, hexagonal boron nitride (h-BN), TMDs) $[15,16]$ or by $2 \mathrm{D}$ material heterojunctions with thin conventional 3D (i.e., bulk) semiconductors [17]. These devices rely on quite different working principles than traditional lateral FETs and mainly exploit vertical current transport across the interfaces of these materials. They include the tunneling field effect transistors (TFETs) [18,19], the band-to-band tunneling transistor [20], the transistor based on the field effect modulation of the Gr/semiconductor Schottky barrier (barristor) [21] and the hot electron transistor (HET) with the base made with a 2D material [22-25]. These devices typically show high ON/OFF current ratios, not reachable by conventional lateral GFETs, that make them suitable for logic and switching applications. Furthermore, some of these device concepts, like the HET with a Gr base, are especially targeted to operate at ultra-high frequencies up to THz.

This paper reviews recent developments in 2D material-based vertical transistors. Section 2 discusses the open issues of Gr and TMD lateral FETs, and it serves to introduce some of the potential advantages of vertical architectures. Therefore, the main vertical device structures considered so far are presented in the Section 3, where the working principles and the targeted application fields for each structure are discussed. In particular, recent implementations of TFET based on 2D materials are overviewed due to their interest in beyond-CMOS digital electronics. Furthermore, recent experimental activity on the HET with Gr base is presented, considering the predicted potential of these devices in ultra-high frequency electronics. In Section 4, the materials science issues and the open challenges for the realization of 2D material vertical transistors at a large scale are illustrated. Finally, the last section includes a summary and some prospects for future industrial applications of the discussed device structures.

\section{Lateral Field Effect Transistors}

Due to the proper bandgap (in the range from 1-2 eV), combined with a good stability under ambient conditions, semiconductor TMDs are very promising candidates as channel materials for digital electronics [13]. As an example, $\mathrm{MoS}_{2}$-channel FETs have been fabricated with large $\mathrm{I}_{\mathrm{on}} / \mathrm{I}_{\text {off }}$ ratios $\left(>10^{4}\right)$ and small subthreshold swings (SS $<80 \mathrm{mV} /$ decade) [26], approaching the desired requirements of FETs for CMOS digital circuits. The energy gap of TMDs comes, however, at the cost of a relatively low mobility. As an example, the upper theoretical limit for the mobility of monolayer $\mathrm{MoS}_{2}$ at room temperature is about $400 \mathrm{~cm}^{2} \mathrm{~V}^{-1} \mathrm{~s}^{-1}$ [27], whereas the experimental values reported so far are in the range of a few tens of $\mathrm{cm}^{2} \mathrm{~V}^{-1} \mathrm{~s}^{-1}[28,29]$.

Besides TMDs, also phosphorene has recently attracted interest as a semiconducting channel material for FETs. A mobility of $286 \mathrm{~cm}^{2} \mathrm{~V}^{-1} \mathrm{~s}^{-1}$ has been reported for few-layer phosphorene [14], whereas values up to $\sim 1000 \mathrm{~cm}^{2} \mathrm{~V}^{-1} \mathrm{~s}^{-1}$ have been shown for multilayer phosphorene with an $\sim 10 \mathrm{~nm}$ thickness [30]. However, the main disadvantage of phosphorene (as compared to TMDs) is its chemical reactivity under ambient conditions, which can represent a serious concern for practical applications.

The ultimate thin body of TMDs can be very beneficial for the scaling prospects of lateral FETs for CMOS applications, as discussed in many simulation works [31-34]. As an example, Liu et al. [33] predicted that $\mathrm{MoS}_{2}$ FETs can meet the requirements of the International Technology Roadmap for Semiconductors (ITRS) [35] down to a minimum channel length of $8 \mathrm{~nm}$. For such aggressively reduced geometries, the low mobility of $\mathrm{MoS}_{2}$ is not a real issue, because transport can be considered as almost 
ballistic for channel lengths below $10 \mathrm{~nm}$. Although most of these predictions are based on simulations, some experimental work has been also reported, where the challenges of channel length scaling in TMD lateral transistors down to the nanometric limit started to be addressed [36].

Concerning high frequency applications, the first Gr-based FET capable of RF operation, fabricated using exfoliated Gr from graphite, was reported in 2008 [37]. Later on, the development of advanced synthesis methods, such as epitaxial growth of $\mathrm{Gr}$ on $\mathrm{SiC}$ by controlled high temperature graphitization [38-41] or chemical vapor deposition (CVD) on catalytic metals [42], provided high quality $\mathrm{Gr}$ of a large area for device fabrication. Ultra-scaled transistors with interesting RF performances have been demonstrated both using transferred CVD Gr [43] (see, e.g., Figure 1a) and epitaxial Gr on SiC (see, e.g., Figure 1b) [43,44].

RF transistors are typically used for the amplification of a high frequency input signal (current or voltage), and the amplifier gain decreases with increasing frequency. Hence, the two main figures of merit for RF transistors are the cut-off frequency $f_{T}$ (i.e., the frequency for which current gain is reduced to unity) and the maximum oscillation frequency $f_{M A X}$ (i.e., the frequency for which power gain is reduced to unity). As in the case of more conventional RF transistors, the $f_{T}$ of GFETs was found to increase with reducing the channel length $\mathrm{L}$ (see, as an example, Figure 1c). A record value of $f_{T}=427 \mathrm{GHz}$ has been reported for scaled devices obtained with a self-aligned fabrication process [11].
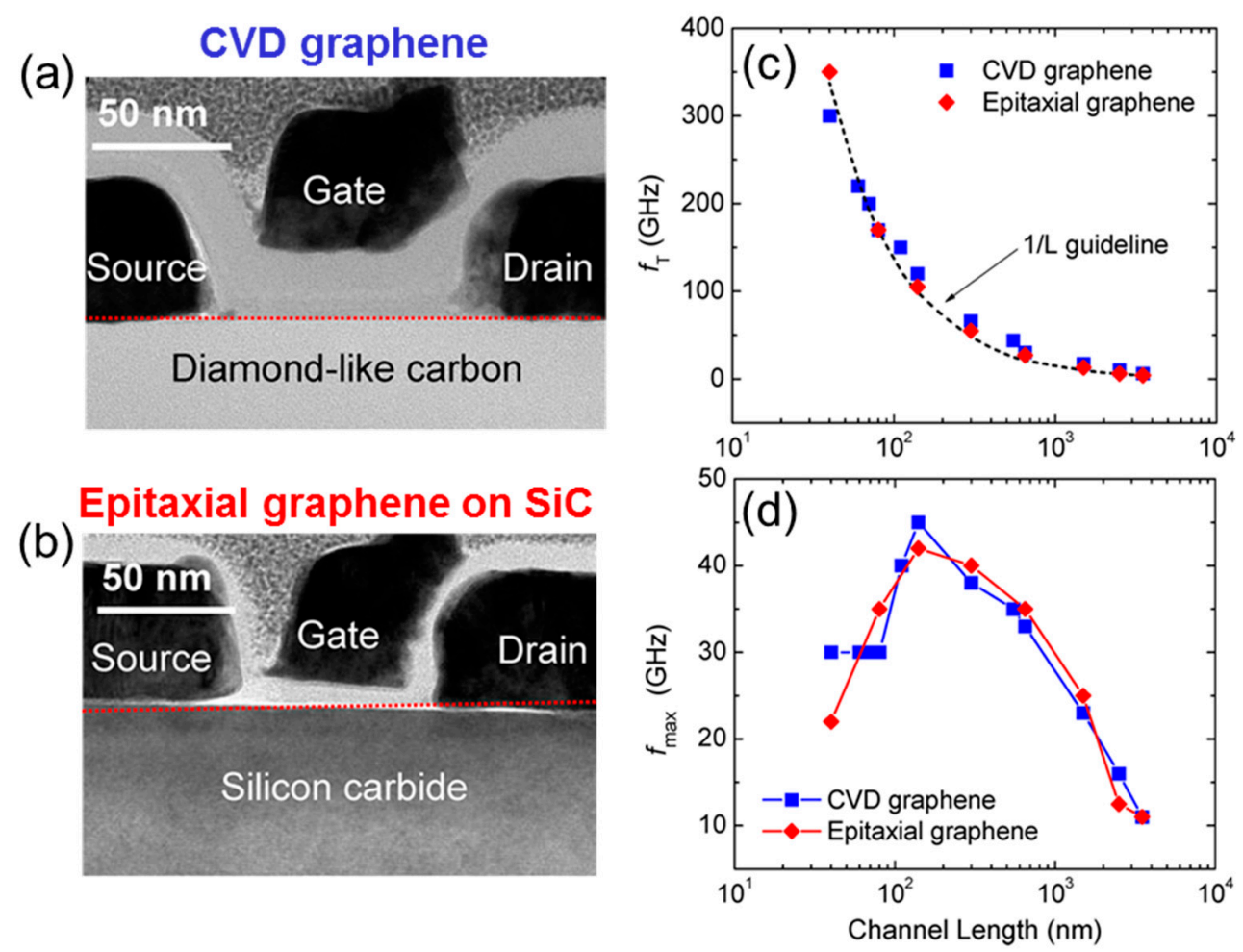

Figure 1. Cross-sectional TEM micrographs of scaled RF graphene (Gr) field effect transistors (GFETs) fabricated with transferred CVD Gr (a) and with epitaxial Gr grown on $\mathrm{SiC}(0001)$ (b); behavior of the cut-off frequency $f_{T}(\mathbf{c})$ and of the maximum oscillation frequency $f_{M A X}(\mathbf{d})$ as a function of channel length. Figures adapted with permission from [43].

These values of $f_{T}$ are comparable with those achieved by the state of the art InP high electron mobility transistors (HEMTs) with similar channel lengths. However, for most RF applications, both high $f_{T}$ and high $f_{M A X}$ are required, and unfortunately, $f_{M A X}$ values measured for GFETs are significantly smaller than $f_{T}$ values, as illustrated in Figure 1d [43]. Furthermore, contrary to common expectations for RF FETs, $f_{M A X}$ shows a non-monotonic behavior with the channel length L. In fact, it reaches a peak value around $150 \mathrm{~nm}$ and decreases for lower $\mathrm{L}$ values. 
The reason for these poorer power gain performances can be argued by comparing the theoretical expressions of $f_{T}$ and $f_{M A X}$ for RF transistors:

$$
\begin{gathered}
f_{T}=\frac{g_{m}}{2 \pi\left(C_{g s}+C_{g d}\right)}\left[\frac{1}{1+g_{d}\left(R_{s}+R_{d}\right)+g_{m} \frac{C_{g d}\left(R_{s}+R_{d}\right)}{C_{g s}+C_{g d}}}\right] \\
f_{M A X}=\frac{f_{T}}{2 \sqrt{g_{d}\left(R_{s}+R_{g s}\right)+2 \pi f_{T} R_{g s} C_{g d}}}
\end{gathered}
$$

Here, $C_{g s}$ and $C_{g d}$ are the gate-source and gate-drain coupling capacitances, $R_{s}$ and $R_{d}$ are the source and drain series resistances, $R_{g s}$ is the gate-source resistance, $g_{m}=\mathrm{dI}_{\mathrm{D}} / \mathrm{dV}_{\mathrm{G}}$ is the transconductance and $g_{d}=\mathrm{dI}_{\mathrm{D}} / \mathrm{dV}_{\mathrm{D}}$ is the output conductance.

The drain current $I_{D}$ of an FET is proportional to the saturated velocity $v_{s}$ and to the sheet concentration $n_{s}$ of the carriers in the channel. Hence, the two prerequisites to achieve a high transconductance are a high $\mathrm{v}_{\mathrm{s}}$ and a high $\mathrm{dn}_{\mathrm{s}} / \mathrm{dV}_{\mathrm{G}}$, i.e., an effective modulation of the carrier density with the gate bias.

If the $R_{S}$ and $R_{d}$ resistance contributions in Equation (1) are properly minimized, the expression of $f_{T}$ can be approximated as $f_{T} \approx g_{m} /\left[2 \pi\left(C_{g s}+C_{g d}\right)\right]$, and it results in being independent of the output conductance $g_{d}$. For this reason the high carrier mobility and saturation velocity of Gr results in a high transconductance $g_{m}$ and, hence, in a high $f_{T}$. On the other hand, from Equation (2), it is evident that, even minimizing $R_{s}$, the output conductance $g_{d}$ still plays a role in the expression of $f_{M A X}$. As a matter of fact, the output characteristics of Gr channel FETs exhibit a poor saturation behavior, i.e., a large $g_{\mathrm{d}}$. This overcompensates the effect of a large $g_{m}$, ultimately resulting in degradation of $f_{M A X}$. The non-monotonic behavior of $f_{M A X}$ in Figure $1 \mathrm{~d}$ has been also ascribed to the competing contributions from $f_{T}, g_{d}$ and $R_{g s}$ as L decreases [43].

The poor saturation of the output characteristics is mainly a consequence of the missing bandgap in the Gr band structure. Hence, this peculiar physical property of Gr not only hinders its application in digital electronics, but severely limits also the high frequency performances of GFETs in terms of power amplification and $f_{M A X}$. Finally, the high off-state current ( $\mathrm{I}_{\text {off }}$ ) of GFETs results in a high power dissipation and represents a significant concern in terms of energy efficiency.

Besides $\mathrm{Gr}$, single and multiple layers of $\mathrm{MoS}_{2}$ have been also investigated as channel materials in lateral FETs for RF applications. Thanks to an electron saturation velocity $\mathrm{v}_{\mathrm{s}}>3 \times 10^{6} \mathrm{~cm} / \mathrm{s}$ [45] and to a high bandgap (resulting in a high ratio $g_{m} / g_{d}>30$ ), $\mathrm{MoS}_{2}$ FETs can achieve, in principle, both current and power amplification [46-49]. However, quite low values of $f_{T}$ and $f_{M A X}$ have been reported to date. Initial work on exfoliated monolayer $\mathrm{MoS}_{2}$ RF FETs yielded $f_{T}=2 \mathrm{GHz}$ and $f_{M A X}=2.2 \mathrm{GHz}$ at a gate length of $240 \mathrm{~nm}$ [48]. Figure 2 shows a cross-sectional TEM micrograph (a) and the DC output (b) and transfer (c) characteristics of an FET fabricated with multilayer $\mathrm{MoS}_{2}$ flakes. For these devices, the scaling behavior of $f_{T}$ and $f_{M A X}$ with the channel length is illustrated in Figure $2 \mathrm{~d}$,e, showing how $f_{T}=42 \mathrm{GHz}$ and $f_{\text {MAX }}=50 \mathrm{GHz}$ are achieved at a gate length of $68 \mathrm{~nm}$ [47]. More recently, RF FET fabricated with monolayer $\mathrm{MoS}_{2}$ deposited by CVD showed $f_{T}=6.7 \mathrm{GHz}$ and $f_{\text {MAX }}=5.3 \mathrm{GHz}$ at a gate length of $250 \mathrm{~nm}$ [49].

Several issues still need to be addressed to evaluate the real potentialities of TMDs both in digital and RF electronics. Besides the issues related to the lattice defects (such as chalcogen vacancies) [50-52] and impurities [53] commonly present in these compound materials, some critical processing steps need to be developed. These include the fabrication of low resistance source/drain contacts $[54,55]$ and doping [56-58]. 

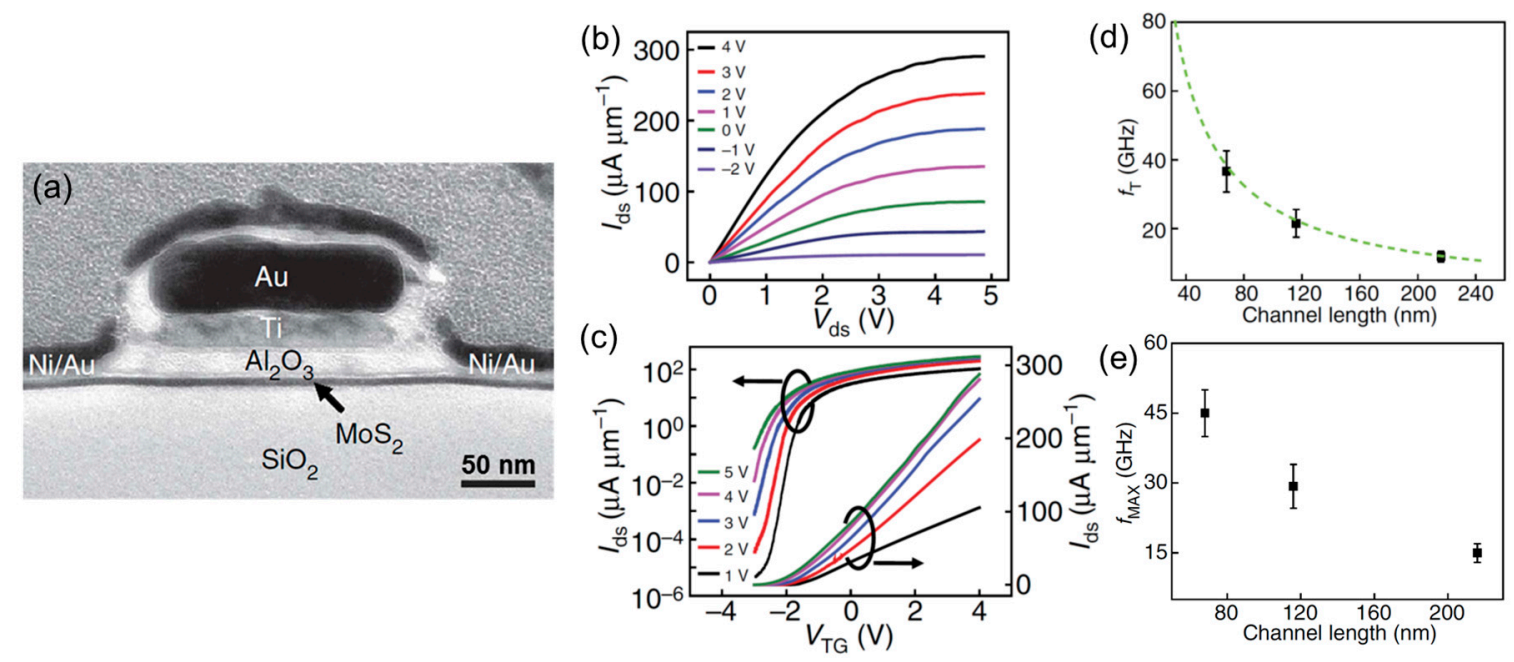

Figure 2. Cross-sectional TEM micrograph (a); DC output (b) and transfer (c) characteristics of an FET fabricated with multilayer $\mathrm{MoS}_{2}$. Scaling behavior of $f_{T}(\mathbf{d})$ and $f_{M A X}(\mathbf{e})$ with the channel length. Figures adapted with permission from [47].

As an example, $\mathrm{MoS}_{2}$ thin films are typically unintentionally $n$-type doped. Furthermore, most of the elementary metals exhibit a Fermi level pinning close to the $\mathrm{MoS}_{2}$ conduction band, resulting in a small (but not negligible) Schottky barrier height (SBH) for electrons' injection and a high SBH for holes' injection. The origin of this Fermi level pinning is still a matter of debate, although some nanoscale electrical investigations highlighted the possible role of the defects present at the $\mathrm{MoS}_{2}$ surface $[59,60]$. As a matter of fact, this Schottky barrier results in a significant source/drain contact resistance $[54,61]$, which degrades the intrinsic performances of the transistor. Furthermore, the high injection barrier for holes makes it difficult to achieve $p$-type or ambipolar transport in $\mathrm{MoS}_{2}$ FETs $[62,63]$. On the other hand, ambipolar transistors can be useful not only for logic (CMOS) applications, but also for some RF circuits. To date, $p$-type $\mathrm{MoS}_{2}$ transistors have been fabricated by using high work function MoOx contacts [64]. Recently, multilayer $\mathrm{MoS}_{2}$ transistors with ambipolar behavior have been demonstrated by selective-area $p$-type doping in the source/drain regions with $\mathrm{O}_{2}$ plasma [65]. Besides $\mathrm{MoS}_{2}$, other TMDs have been also considered for FETs' fabrication. As an example, $\mathrm{WSe}_{2}$ is a slightly $p$-doped semiconductor, allowing the fabrication of both $p$-type and $n$-type FETs by proper selection of the metal contacts [66-68]. However, the problem of the contact resistance still holds also in the case of $\mathrm{WSe}_{2}$.

Most of the TMD-based FETs have been fabricated using metals as source-drain contacts and high permittivity (high-k) dielectrics as gate insulators. Recently, some attempts at fabricating FETs with all components formed by 2D materials have been reported. As an example, Roy and co-workers have demonstrated an FET including $\mathrm{MoS}_{2}$ as the channel material, h-BN as the dielectric layer for top electrode isolation and $\mathrm{Gr}$ for semi-metal contacts (see the schematic and the optical microscopy in Figure 3a,b) [69]. An optimal Ohmic contact between $\mathrm{Gr}$ and $\mathrm{MoS}_{2}$ is possible by tuning the $\mathrm{Gr}$ Fermi level by the $\mathrm{SiO}_{2}$ /Si back-gate bias. Due to its large bandgap, h-BN acts as a top-gate dielectric, allowing current modulation over several orders of magnitude (see Figure 3c). Furthermore, thanks to its atomically-smooth surface without charge trapping, h-BN forms an ideal interface with the $\mathrm{MoS}_{2}$ channel [3]. One of the most relevant advantages of this smooth interface is that the channel mobility of this device remains constant at high gate bias values (see Figure 3d), different from that in common FETs, where a decrease of mobility is observed at high fields due to the effect of the interface roughness. 

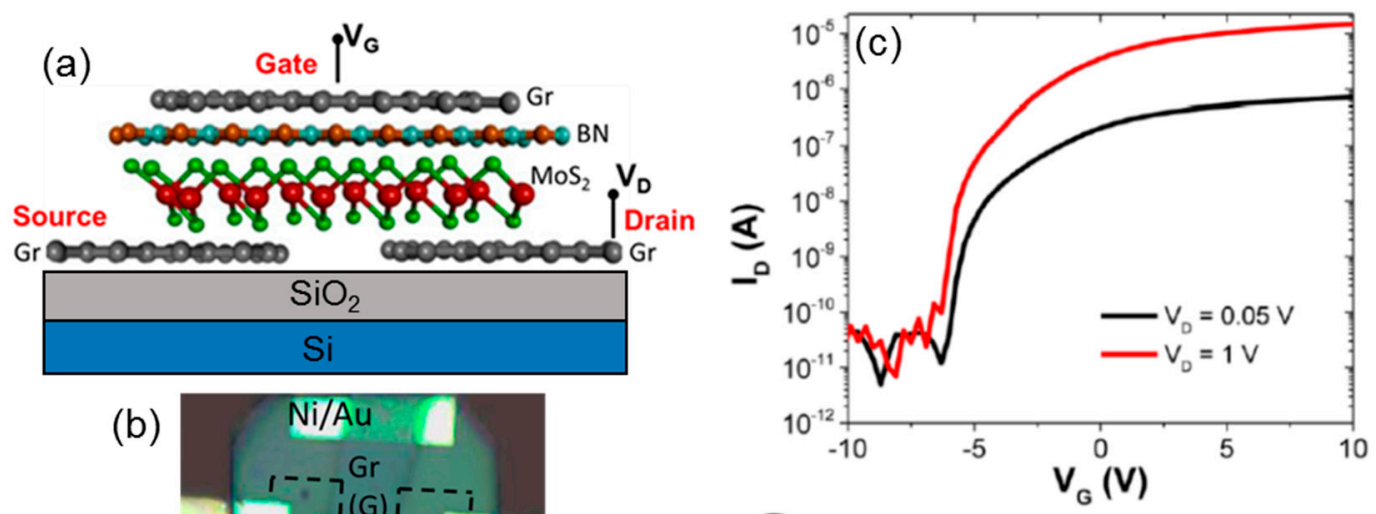

(b)
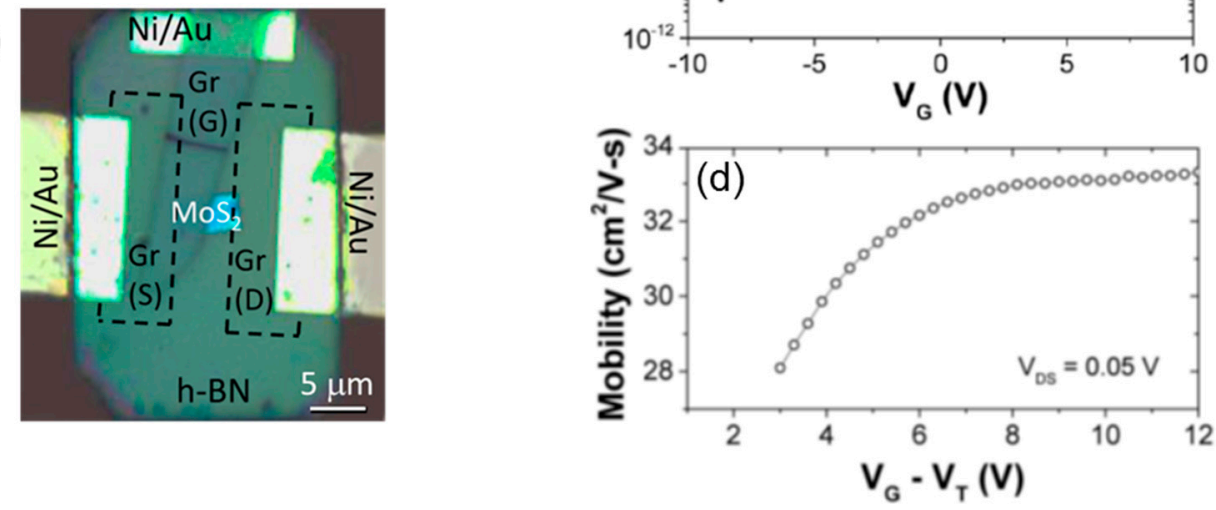

Figure 3. Schematic (a) and optical microscopy (b) of an FET with all components formed by 2D materials, where $\mathrm{MoS}_{2}$ works as the channel, hexagonal boron nitride (h-BN) as the dielectric layer for top electrode isolation and Gr for semimetal source/drain contacts. Transfer characteristics (c) and mobility vs. gate bias behavior (d) of this transistor. Figures adapted with permission from [69]

\section{Vertical Transistors}

\subsection{Tunneling Field Effect Transistors}

One of the main issues for modern digital electronics is the dramatic increase of power consumption with the increase in the device integration density. As a matter of fact, the minimum supply voltage to switch an MOSFET from the OFF to the ON state is determined by the thermionic emission mechanism of carrier injection over the energy barrier at the source. This mechanism results in a theoretical limit of $60 \mathrm{mV} /$ decade for the minimum subthreshold swing (SS) for MOSFET devices. On the other hand, tunneling field effect transistors (TFETs), based on quantum mechanical tunneling across an energy barrier, have the potential of reduced supply voltage, since a pure tunneling process is not thermally activated. Numerous studies have been conducted in the last decade to implement this device concept using bulk (3D) semiconductors, such as Ge, III-V and Si [70,71], and sub-thermionic SS values have been reported with TFETs based on these materials. However, the demonstrated performances have not been good enough for practical applications. In particular, one of the main limitations is that $\mathrm{SS}<60 \mathrm{mV} /$ decade (at room temperature) is typically obtained only at low drain currents, whereas it would be desirable to get such a behavior over a current range of several orders of magnitude. One of the reasons for the difficulty in obtaining sharp switching over a wide current range is the presence of band-tail states in bulk semiconductors [72]. Under this point of view, 2D materials with sharp band edges even at a thickness of a monolayer can represent an interesting platform to implement TFETs.

Britnell and co-workers first reported a TFET with the vertically-stacked heterostructure composed of Gr and thin h-BN [18]. Figure 4a schematically shows the layer stacking (1); the energy band diagram under equilibrium (2); under the effect of the back-gate bias $V_{g}(3)$; and under the effect of $V_{g}$ and of a bias $V_{b}$ between the two Gr layers (4). The basic principle of this vertical transistor is the quantum tunneling between the two Gr electrodes separated by the thin h-BN barrier. Current tunneling was controlled by tuning the density of states in Gr and the associated barrier by the external gate 
voltage. Figure $4 \mathrm{~b}$ shows the tunneling current density $\mathrm{J}$ vs. the bias $\mathrm{V}_{\mathrm{b}}$ for different values of $\mathrm{V}_{\mathrm{g}}$. Figure $4 c$ shows the conductance $d J / d V_{b}\left(a t V_{b}=0\right)$ as a function of $V_{g}$, from which an ON/OFF ratio of $\sim 50$ was deduced.
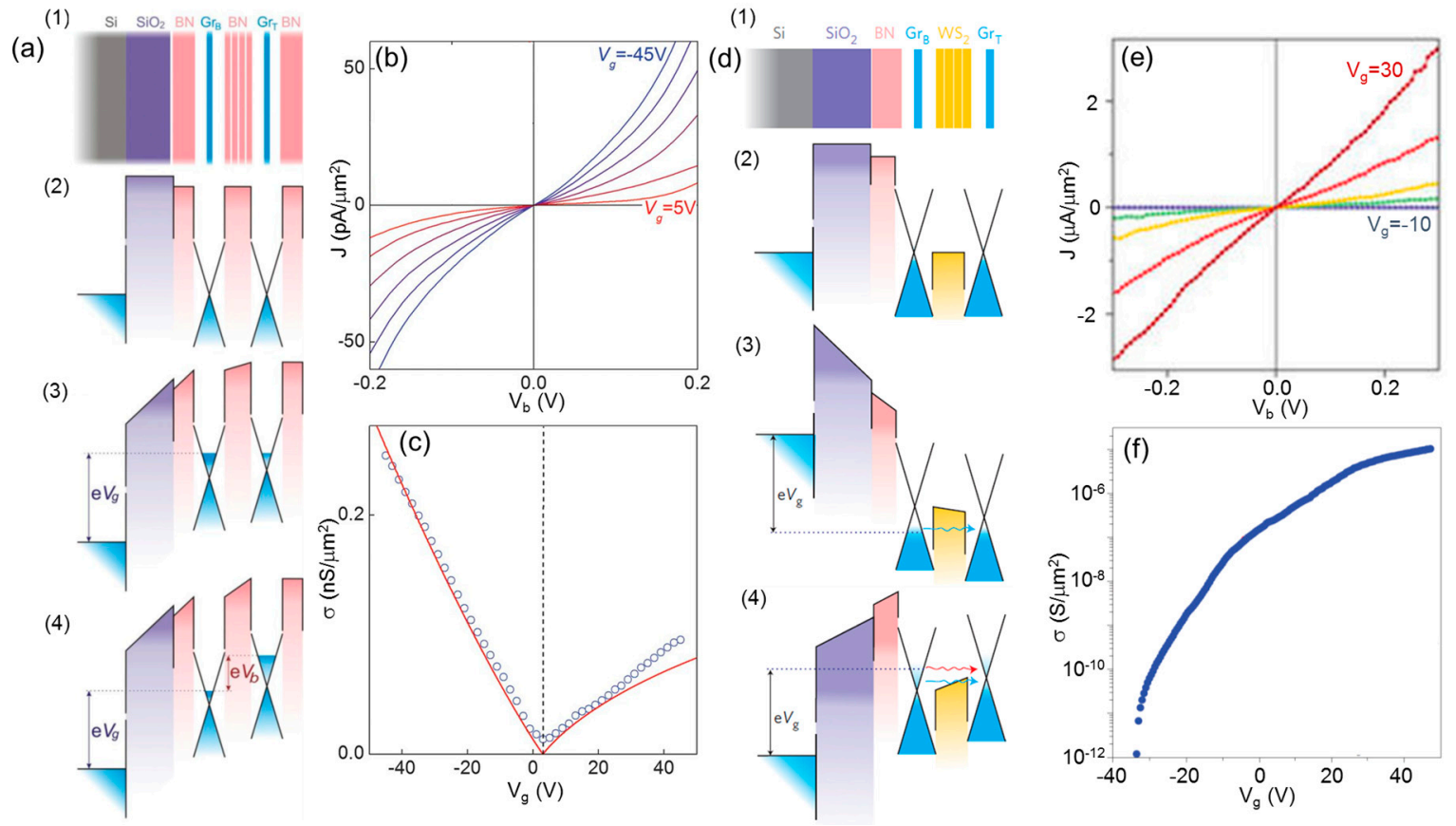

Figure 4. (a) Schematic illustration of a Gr/h-BN/Gr field effect tunneling transistor: (1) layer stacking; (2) energy band diagrams under equilibrium; (3) under the effect of the back-gate bias $\mathrm{V}_{g}$; and (4) under the effect of $V_{g}$ and of a bias $V_{b}$ between the two Gr layers; (b) tunneling current density $J$ vs. $V_{b}$ for different values of $\mathrm{V}_{\mathrm{g}}$; (c) conductance $\sigma=\mathrm{dJ} / \mathrm{dV}_{\mathrm{b}}$ as a function of $\mathrm{V}_{\mathrm{g}}$; (d) schematic illustration of a Gr/WS $/$ /Gr field effect tunneling transistor: (1) layer stacking; (2) energy band diagrams under equilibrium; (3) under the effect of $\mathrm{V}_{\mathrm{g}}<0$; and (4) under the effect of $\mathrm{V}_{\mathrm{g}}>0$; (e) tunneling current density J vs. $V_{b}$ for different values of $V_{g} ;(f)$ conductance $\sigma=d J / d V_{b}$ as a function of $V_{g}$. Figures adapted with permission from $[18,19]$.

As the transit time associated with tunneling is very low, the field effect tunneling transistor can be potentially suitable for high speed operation. On the other hand, as a result of the direct tunneling mechanism, this device suffers from very low current density (in the order of $10-100 \mathrm{pA} / \mu \mathrm{m}^{2}$ ), making it not useful for practical applications. Starting from the same idea, Georgiou and co-workers reported a Gr vertical FET with $\mathrm{WS}_{2}$ layers as the barrier [19]. Figure $4 \mathrm{~d}$ schematically shows the layer stacking (1); and the energy band diagrams under equilibrium (2); under the effect of $V_{g}<0$ (3); and under the effect of $\mathrm{V}_{\mathrm{g}}>0$ (4). Due to the smaller band gap of $\mathrm{WS}_{2}$, current transport between the two Gr layers occurs by direct tunneling for $\mathrm{V}_{\mathrm{g}}<0$ and by tunneling or thermionic emission for $\mathrm{V}_{\mathrm{g}}>0$. Figure $4 \mathrm{e}$ shows the tunneling current density $\mathrm{J}$ vs. the bias $\mathrm{V}_{\mathrm{b}}$ for different values of $\mathrm{V}_{\mathrm{g}}$, whereas Figure $4 \mathrm{f}$ shows the conductance as a function of $\mathrm{V}_{\mathrm{g}}$. As compared to the $\mathrm{Gr} / \mathrm{h}-\mathrm{BN} / \mathrm{Gr}$ prototype, this device exhibits much higher $\mathrm{ON}$ current (in the order of $1 \mu \mathrm{A} / \mu \mathrm{m}^{2}$ ) and better current modulation, with an ON/OFF current ratio up to $10^{6}$.

\subsubsection{Resonant Interlayer Tunneling Transistors}

Progress in the alignment and transfer techniques of 2D materials permitted the demonstration of resonant tunneling phenomena in TFETs. Devices showing gate-tunable negative differential resistance (NDR) of the output characteristics due to resonant tunneling were first obtained by $\mathrm{Gr} / \mathrm{h}-\mathrm{BN} / \mathrm{Gr}$ stacks with a precise rotational crystallographic alignment between the two Gr monolayers [73,74]. Since carriers in a Gr monolayer are populated near the K-point on the periphery of its Brillouin zone, 
conservation of both energy and momentum in the tunneling from one layer to the other is allowed only in the presence of a rotational alignment in momentum space.

Following the first demonstrations with double monolayer Gr, resonant TFET using bilayer Gr as the top and bottom electrodes and $\mathrm{h}-\mathrm{BN}$ as the interlayer tunnel barrier were also demonstrated $[75,76]$. Due to the more complex band structure of bilayer Gr (with two sub-bands both in the conduction and valence bands at the K-point), additional NDR peaks occur at higher interlayer bias [75]. In fact, when the first sub-band of one bilayer energetically aligns with the second sub-band of the opposite bilayer, a second resonant tunneling condition is established. More recently, experimental results for resonant TFETs with multilayer Gr electrodes separated by an h-BN tunnel barrier have been also reported [77]. With an increase in the Gr electrode layer thickness, from bilayer to pentalayer Gr, the resonance peaks have been shown to become narrower in width and stronger in intensity, mainly due to the increase in the density of states with the increase in the Gr thickness. On the other hand, due to the increased complexity in the band structure with multiple sub-bands for thicker Gr, multiple resonance conditions arise in the output characteristics.

h-BN has been widely used as the interlayer in resonant TFETs with symmetric Gr electrodes, due to its good insulating properties and chemically-inert and atomically-flat surface. However, its wide energy bandgap $(\sim 5.8 \mathrm{eV})$ severely limits the peak current at resonance in $\mathrm{Gr} / \mathrm{h}-\mathrm{BN} / \mathrm{Gr}$ TFETs [77]. In this context, using TMDs with a smaller bandgap as tunnel barriers may enhance the peak-to-valley ratio of the resonances in the electrical characteristics. Recently, Burg et al. [78] demonstrated gate-tunable resonant tunneling and NDR between two rotationally-aligned bilayer $\mathrm{Gr}$ sheets separated by a bilayer $\mathrm{WSe}_{2}$. Remarkable large interlayer current densities of $2 \mu \mathrm{A} / \mu \mathrm{m}^{2}$ and NDR peak-to-valley ratios of $\sim 4$ were observed at room temperature in these device structures.

Recently, the possibility of realizing resonant TFETs using TMD electrodes instead of Gr has been also considered $[79,80]$. Theoretical reports indicate that vertical heterostructures consisting of two identical monolayer $\mathrm{MoS}_{2}$ electrodes separated by an h-BN barrier can result in a peak-to-valley ratio several orders of magnitude higher than the best that can be achieved using Gr electrodes [79]. However, practical implementation of resonant tunneling TFETs with identical electrodes (different than Gr) proved to be difficult.

On the other hand, many vertical transistor demonstrators have been implemented with differing bottom and top electrode layers, exploiting the principle of band-to-band tunneling, as discussed in the following.

\subsubsection{Band-To-Band Tunneling Vertical Transistor}

Roy et al. [81] first experimentally demonstrated interlayer band-to-band tunneling in vertical $\mathrm{MoS}_{2} / \mathrm{WSe}_{2}$ vdW heterostructures using a dual-gate device architecture. The electric potential and carrier concentration of the $\mathrm{MoS}_{2}$ and $\mathrm{WSe}_{2}$ layers were independently controlled by the two symmetric gates. Depending on the gate bias, the device behaves as either an Esaki diode with NDR, a backward diode with large reverse bias tunneling current or a forward rectifying diode with low reverse bias current. Notably, the weak electrostatic screening by the atomically thin $\mathrm{MoS}_{2}$ and $\mathrm{WSe}_{2}$ layers resulted in a high gate coupling efficiency for tuning the interlayer band alignments. Later on, Nourbakhsh et al. [82] further investigated band-to-band tunneling in the transverse and lateral directions of the $\mathrm{MoS}_{2} / \mathrm{WSe}_{2}$ heterojunctions. The room-temperature NDR in a heterojunction diode formed by few-layer $\mathrm{WSe}_{2}$ stacked on multilayer $\mathrm{MoS}_{2}$ was attributed to the lateral band-to-band tunneling at the edge of this heterojunction.

A band-to-band tunneling vertical transistor has been demonstrated also using the vdW heterojunction between differently-doped layered semiconductors as $\mathrm{WSe}_{2}$ and $\mathrm{SnSe}_{2}$, where $\mathrm{WSe}_{2}$ worked as the back-gate-controlled $p$-layer and $\mathrm{SnSe}_{2}$ was the degenerately $n$-type-doped layer [83].

Yan et al. [84] demonstrated room temperature Esaki tunnel diodes using a vdW heterostructure made of two layered semiconductors with a broken-gap energy band offset: black phosphorus (BP) and tin diselenide $\left(\mathrm{SnSe}_{2}\right)$. The presence of a thin insulating barrier between $\mathrm{BP}$ and $\mathrm{SnSe}_{2}$ enabled the 
observation of a prominent NDR region in the forward-bias current voltage characteristics, with a peak to valley ratio of 1.8 at $300 \mathrm{~K}$ and a weak temperature dependence, indicating electron tunneling as the dominant transport mechanism.

Another recently demonstrated very interesting device concept is based on the field effect modulation of current transport across the $p-n$ heterojunction between $3 \mathrm{D}$ and 2D semiconductors. The 3D semiconductor component of the heterojunction is heavily doped in equilibrium by substitutional dopants, whereas the doping level of the 2D semiconductor component can be tuned by the field effect. Therefore, gate-tunable 2D-3D $p-n$ heterojunctions provide a unique opportunity to realize band-to-band tunneling devices. As an example, Sarkar and co-workers have recently demonstrated a band-to-band tunnel FET with a vertical heterojunction between a $p$-type Ge and an $n$-type bilayer $\mathrm{MoS}_{2}$ [20] (see the schematic representation in Figure 5a). The band diagrams for the device in the OFF and ON states are illustrated in Figure $5 b$ and the transfer characteristics in Figure $5 c$. By gating the $\mathrm{MoS}_{2}$ into the high $n$-type doping regime, direct tunneling occurs from the Ge valence band to the $\mathrm{MoS}_{2}$ conduction band. Figure 5d illustrates the values of the SS at room temperature as a function of the drain current for this bilayer $\mathrm{MoS}_{2} / p$-Ge TFET and for a conventional MOSFET fabricated with a bilayer $\mathrm{MoS}_{2}$ channel. Different from the conventional FET, this TFET exhibits an SS lower than the thermionic limit of $60 \mathrm{mV} /$ decade in the considered drain current range (from $10^{-13}$ to $\left.10^{-9} \mathrm{~A}\right)$. On the other hand, for larger drain currents, significantly larger SS values are obtained.

(a)
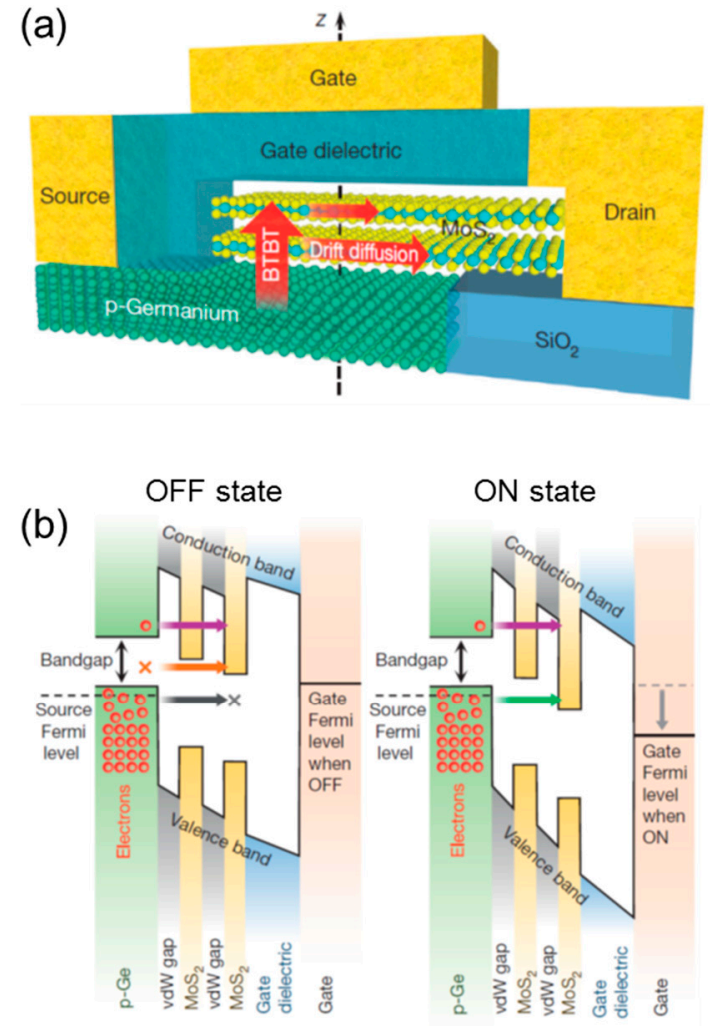

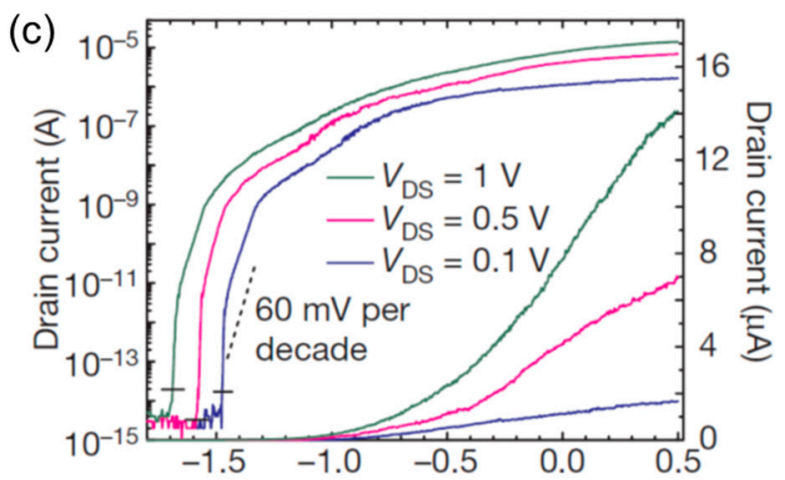

(d)

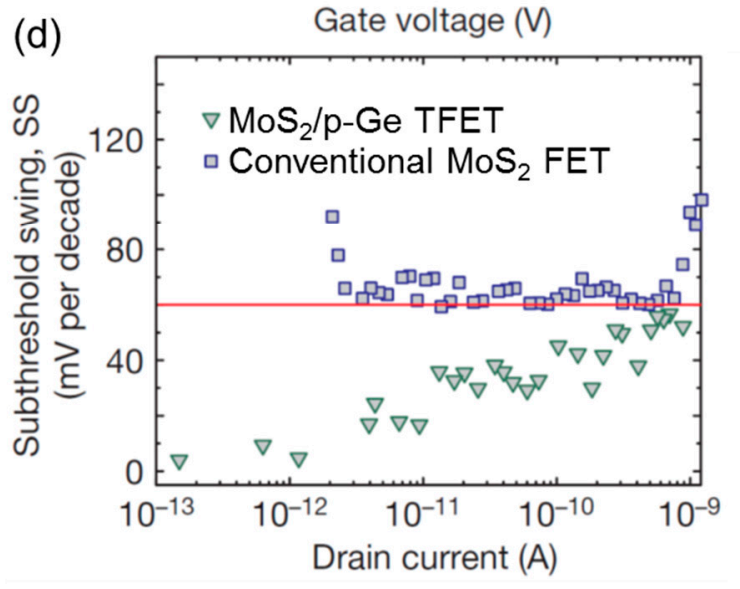

Figure 5. (a) Schematic cross-section of a gate-modulated bilayer $\mathrm{MoS}_{2} / p$-Ge junction; (b) band diagrams of the device in the OFF and ON state; (c) transfer characteristics of the device for different $\mathrm{V}_{\mathrm{DS}}$; (d) comparison of the subthreshold swing (SS) of this bilayer $\mathrm{MoS}_{2} / p$-Ge tunneling field effect transistor (TFET) with that of a conventional FET with a bilayer $\mathrm{MoS}_{2}$ channel. Figures adapted with permission from [20]. 


\subsection{Gate Modulated Schottky Barrier Transistor (Barristor)}

The Barristor device concept is based on the tunability of the Schottky barrier height of a Gr contact with a semiconductor by an external electric field. Clearly, a nearly ideal interface between Gr and the semiconductor, without interface states responsible for Fermi level pinning, is required to achieve an efficient field effect modulation of the Schottky barrier height. The first Barristor was demonstrated by transferring CVD graphene onto hydrogen-passivated $\mathrm{Si}$, thus obtaining a nearly ideal Schottky diode behavior both with $n$ - and $p$-type $\mathrm{Si}$ [21]. Figure 6a illustrates a cross-sectional schematic of a Gr/Si barristor, and Figure $6 \mathrm{~b}$ shows the band diagram for the $\mathrm{Gr} / n$-Si Schottky junction for $\mathrm{V}_{\mathrm{g}}>0$ and $\mathrm{V}_{\mathrm{g}}<0$. The modulation of the $\mathrm{Gr} / n$-Si Schottky barrier height with the gate bias is shown in Figure $6 c$, and the resulting output characteristics of the device (for different $V_{g}$ values) are reported in Figure $6 \mathrm{~d}$. A current ON/OFF ratio of $\sim 10^{5}$ under forward bias was achieved, which is suitable for digital logic applications.
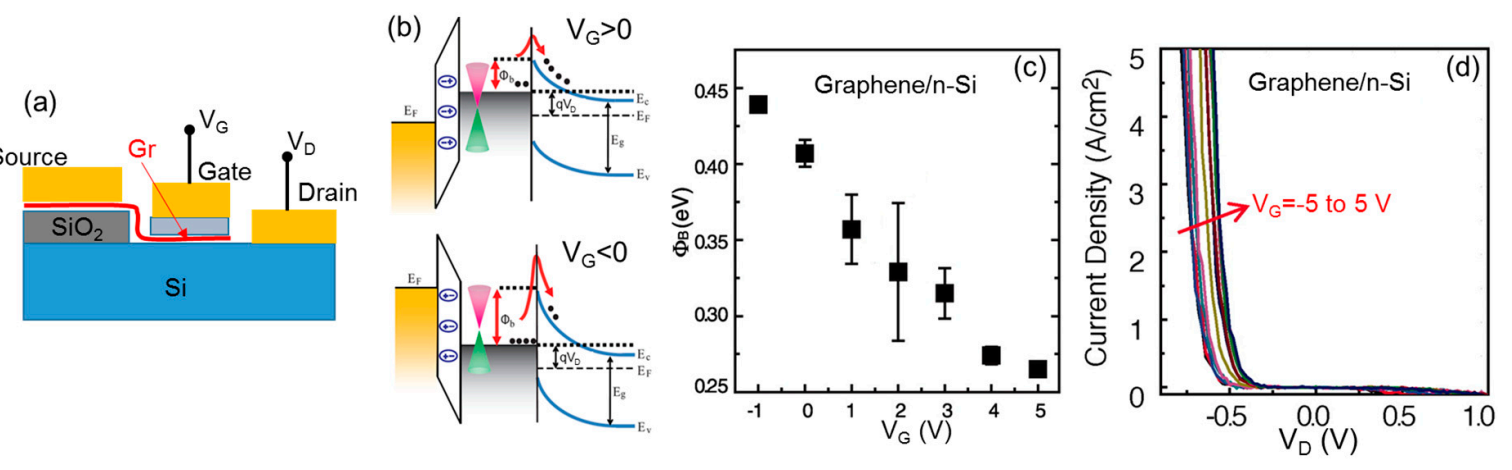

Figure 6. (a) Schematic cross-section of a Gr/Si Barristor; (b) band-diagrams of the Gr/n-Si device for $\mathrm{V}_{\mathrm{g}}>0$ (a) and $\mathrm{V}_{\mathrm{g}}<0$; (c) behavior of the $\mathrm{Gr} / n$-Si Schottky barrier height vs. the gate voltage $\mathrm{V}_{\mathrm{g}}$; (d) Current density vs. $V_{D}$ for different $V_{g}$ from -5 to 5 V. Figures adapted with permission from [21].

The early demonstration of the Barristor was based on the vdW heterostructure between a 2D material (i.e., Gr) and a 3D material (i.e., Si). More recently, a vertical transistor working on the same principle has been demonstrated using the 2D/2D vdW heterostructure between Gr and a TMD. Also in this case, current modulation was obtained by electric-field tuning of the Schottky barrier between Gr and the TMD, whereas a proper metal layer provides an Ohmic contact with the TMD. $\mathrm{Yu}$ and coworkers have demonstrated such a device with a $\mathrm{Gr} /$ few-layer $\mathrm{MoS}_{2} /$ metal heterostructure. This FET showed an ON/OFF ratio larger than 100 and a high current density of $5000 \mathrm{~A} / \mathrm{cm}^{2}$ [85]. Moriya and co-workers further improved the current modulation to $>10^{5}$ and current density up to $10^{4} \mathrm{~A} / \mathrm{cm}^{2}$ with a similar structure, but better interface fabrication [86]. The advantages of this type of vertical transistor are the large current density and the small device scale, providing high potential for future high density integration circuits.

\subsection{Hot Electron Transistor}

The hot electron transistor (HET) is a three-terminal (i.e., emitter, base and collector) heterostructure device where the ultra-thin base layer is sandwiched between two thin insulating barriers (i.e., the emitter-base and base-collector barriers), as schematically illustrated in Figure 7a. For a sufficiently high forward bias $\mathrm{V}_{\mathrm{BE}}$ applied between the base and the emitter, electrons are injected into the base by Fowler-Nordheim (FN) tunneling through the barrier or by thermionic emission above the barrier, depending on the barrier height and thickness. A key aspect for the HET operation is that the injected electrons (hot electrons) have a higher energy compared to the Fermi energy of the electrons' thermal population (cold electrons) in the base. Ideally, for a base thickness lower than the scattering mean free path of hot electrons, a large fraction of the injected electrons can traverse the base ballistically, i.e., without losing energy, and finally reach the edge of the base-collector barrier. 
This barrier is aimed to act as an energy filter, which allows the hot electrons to reach the collector and reflects back the electrons with insufficient energy. These reflected electrons eventually become part of the cold electrons' population in the base and contribute to base current $\left(\mathrm{I}_{\mathrm{B}}\right)$, whereas the hot electrons reaching the collector give rise to the collector current $\left(\mathrm{I}_{\mathrm{C}}\right)$. Besides transmitting hot electrons, the base-collector barrier must be thick and high enough to block the leakage current $\mathrm{I}_{\mathrm{BCleak}}$ of cold electrons from the base to the collector.

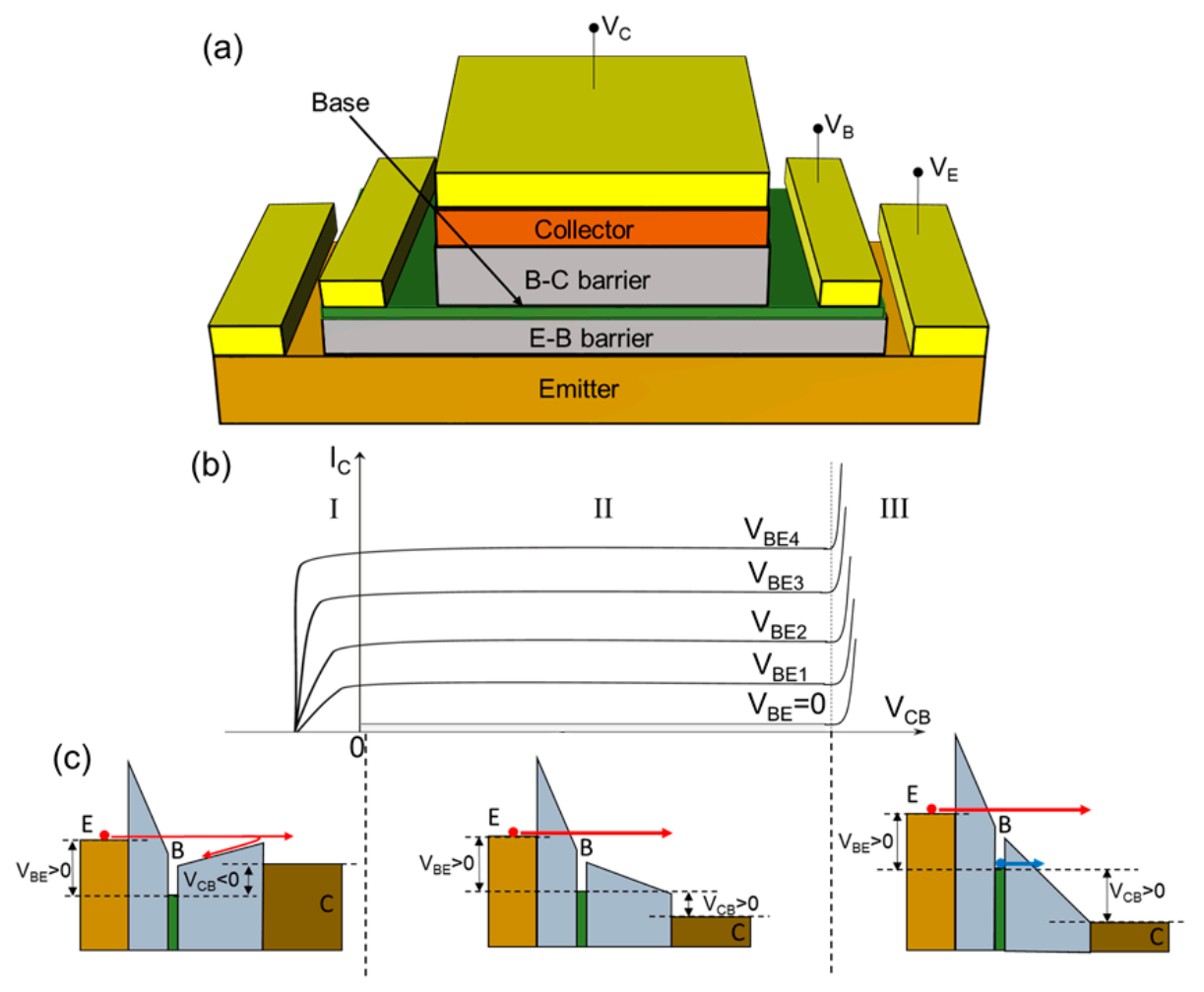

Figure 7. (a) Schematic illustration of a hot electron transistor (HET); (b) ideal output characteristics $I_{C}-V_{C B}$ for the transistor biased in the common-base configuration $\left(V_{B}=0\right.$ and $\left.V_{B E}=V_{B}-V_{E}>0\right)$ for different $V_{B E}$ values; (c) energy band diagrams for different $V_{C B}$ biasing regimes.

Figure $7 \mathrm{~b}, \mathrm{c}$ illustrates the DC electrical characteristics and the band diagrams for an HET biased in the common-base configuration (i.e., with $V_{B}=0$ and $V_{B E}=V_{B}-V_{E}>0$ ). Depending on the values of the potential difference $V_{C B}=V_{C}-V_{B}$, three current transport regions can be observed in the output characteristics $\mathrm{I}_{C}-\mathrm{V}_{\mathrm{CB}}$ (Figure $7 \mathrm{~b}$ ). For $\mathrm{V}_{\mathrm{CB}}>0$ (Region II), $\mathrm{I}_{\mathrm{C}}$ is almost independent of $\mathrm{V}_{\mathrm{CB}}$, i.e., all the injected hot electrons are transmitted above the $\mathrm{B}-\mathrm{C}$ barrier (current saturation regime of the transistor). For $\mathrm{V}_{\mathrm{CB}}<0$ (Region I), the collector edge of the $\mathrm{B}-\mathrm{C}$ barrier is raised up, and part of the hot electrons is reflected back in the base, resulting in a decrease of $\mathrm{I}_{C}$ with increasing negative values of $\mathrm{V}_{\mathrm{CB}}$, up to device switch-off. For large positive values of $\mathrm{V}_{\mathrm{CB}}$ (Region III), the leakage current $\left(\mathrm{I}_{\mathrm{BCleak}}\right)$ contribution of cold electrons injected by FN tunneling through the B-C barrier becomes large, and this leads to a rapid increase of $\mathrm{I}_{C}$ as a function of $\mathrm{V}_{\mathrm{CB}}$.

The main figures of merits for DC operation of an HET are the common-base current transfer ratio $\alpha=\mathrm{I}_{\mathrm{C}} / \mathrm{I}_{\mathrm{E}}$ and the common-emitter current gain $\beta=\mathrm{I}_{\mathrm{C}} / \mathrm{I}_{\mathrm{B}}$. For good DC performances, $\alpha \approx 1$ and $\beta$ as large as possible are needed.

In the case of an HET, the high-frequency figures of merit, i.e., the cutoff frequency $f_{T}$ and the maximum oscillation frequency $f_{M A X}$, can be expressed as follows:

$$
f_{T}=\frac{1}{2 \pi\left(\tau_{d}+\frac{C_{E B}+C_{B C}}{g_{m}}\right)}
$$




$$
f_{M A X}=\sqrt{\frac{f_{T}}{2 \pi R_{B} C_{B C}}}
$$

where $\tau_{d}$ is the total delay time associated with electrons' transit in the E-B barrier layer, in the base and in the B-C filtering layer, $C_{E B}$ and $C_{B C}$ are the capacitances of the two barriers, $g_{m}=\mathrm{dJ}_{C} / \mathrm{dV}_{\mathrm{BE}}$ is the transconductance and $R_{B}$ is the base resistance. Clearly, the most effective way to maximize $f_{T}$ is the increase of $g_{m}$. In fact, a reduction of the barrier layer capacitances would imply an increase of the E-B and B-C barrier thicknesses, with a consequent impact on the transit delay times across these barriers. Under saturation conditions, when all the hot electrons injected from the emitter reach the collector $\left(\mathrm{J}_{\mathrm{C}} \approx \mathrm{J}_{\mathrm{E}}\right)$, the transconductance $g_{m} \approx \mathrm{dJ}_{\mathrm{E}} / \mathrm{dV}_{\mathrm{BE}}$. As the emitter current is injected over a barrier, it exhibits an exponential dependence on $\mathrm{V}_{\mathrm{BE}}$, i.e., $\mathrm{J}_{\mathrm{E}} \propto \exp \left(\mathrm{q} \mathrm{V}_{\mathrm{BE}} / \mathrm{kT}\right)$. As a result, $g_{m} \propto \mathrm{qJ}_{\mathrm{E}} / \mathrm{kT}$. This means that a high injection current density is one of the main requirements to achieve a high cut-off frequency $f_{T}$. The $R_{B}$ term in Equation (4) is the resistance associated with "lateral" current transport in the base layer from the device active area to the base contact. Hence, $R_{B}$ is the sum of different contributions, i.e., the "intrinsic" base resistance $R_{B_{-} \text {int }} \propto \rho / d_{B}$ (with $\rho$ the base resistivity and $d_{B}$ the base thickness), the resistance of the Ohmic metal contact with the base and the access resistance from this contact to the device active area. All these contributions should be minimized to achieve a low $R_{B}$. Of course, the most challenging issue to obtain high $f_{M A X}$ is to fabricate an ultra-thin base (allowing ballistic transport of hot electrons in the vertical direction) while maintaining low enough intrinsic and extrinsic base resistances. However, for most of the bulk materials, reducing the film thickness to the nanometer or sub-nanometer range implies an increase of the resistivity, due to the dominance of surface roughness and/or grain boundaries' scattering, as well as to the presence of pinholes and other structural defects in the film.

Indeed, the HET device concept was introduced more than 50 years ago by Mead [87]. Since then, several material systems have been considered for HET implementation, including metal thin films [87-90], complex oxides [91], superconducting materials [92], III-V and III-nitride semiconductor heterostructures [93-97]. However, the successful demonstration of high-performance HETs has been limited by the difficulty to scale the base thickness below the electron mean free path of the carriers. In this context, 2D materials, in particular Gr and TMDs, can represent ideal candidates to fabricate the base of HETs, since they maintain excellent conduction properties and structural integrity down to single atomic layer thickness, allowing one to overcome the base scalability issue.

Theoretical studies have predicted that, with an optimized structure, $f_{T}$ and $f_{\text {MAX }}$ up to several terahertz [98], $\mathrm{I}_{\mathrm{on}} / \mathrm{I}_{\text {off }}$ over $10^{5}$, high current and voltage gains can be achieved with a Gr-based HET (GBHET). The first experimental prototypes of GBHETs were reported by Vaziri et al. [22] and by Zeng et al. [23] in 2013. Those demonstrators were fabricated on Si wafers using a CMOS-compatible technology and were based on metal/insulator $/ \mathrm{Gr} / \mathrm{SiO}_{2} / \mathrm{n}^{+}$-Si stacks, where $\mathrm{n}^{+}$-doped $\mathrm{Si}$ substrate worked as the emitter, a few nm thick $\mathrm{SiO}_{2}$ as the E-B barrier, a thicker high-k insulator $\left(\mathrm{Al}_{2} \mathrm{O}_{3}\right.$ or $\mathrm{HfO}_{2}$ ) as the B-C barrier and the topmost metal layer as the collector. Figure 8a shows a schematic of the device structure, while Figure $8 \mathrm{~b}$ illustrates the band diagrams in the OFF and ON states. The measured common-base output characteristics of this device are reported in Figure $8 c$, showing a collector current $\mathrm{I}_{\mathrm{C}}$ nearly independent of $\mathrm{V}_{\mathrm{CB}}$ and strongly dependent on $\mathrm{V}_{\mathrm{BE}}$.

In spite of the wide modulation of $\mathrm{I}_{\mathrm{C}}$ as a function of $\mathrm{V}_{\mathrm{BE}}$, these first prototypes suffered from a high threshold voltage and a very poor injected current density (in the order of $\mu \mathrm{A} / \mathrm{cm}^{2}$ ) due to the high $\mathrm{Si} / \mathrm{SiO}_{2}$ barrier, hindering their application at high frequencies.

In order to improve the current injection efficiency, other materials have been investigated as E-B barrier layers in replacement of $\mathrm{SiO}_{2}$ [99]. As an example, using a $6 \mathrm{~nm}$-thick $\mathrm{HfO}_{2}$ (including a 0.5-nm interfacial $\mathrm{SiO}_{2}$ ) deposited by atomic layer deposition results in an improved threshold voltage and a higher injected current density. Further improvements have been obtained using a $\mathrm{TmSiO} / \mathrm{TiO}_{2}$ $(1 \mathrm{~nm} / 5 \mathrm{~nm}$ ) bilayer, where the thin TmSiO layer (with low electron affinity) in contact with the $\mathrm{Si}$ emitter allows high current injection by step tunneling, while the thicker $\mathrm{TiO}_{2}$ layer (with higher electron affinity) serves to block the leakage current from the Si valence band. For this GBHET 
with a $\mathrm{TmSiO} / \mathrm{TiO}_{2}$ E-B barrier, a collector current density $\mathrm{J}_{\mathrm{C}} \approx 4 \mathrm{~A} / \mathrm{cm}^{2}$ (more than five orders of magnitude higher than in the first prototypes) was obtained at $\mathrm{V}_{\mathrm{BE}}=5 \mathrm{~V}$ and for $\mathrm{V}_{\mathrm{BC}}=0$. However, the device still suffers from low values of $\alpha \approx 0.28$ and $\beta \approx 0.4$, which can be due to the insufficient quality of the interface between $\mathrm{Gr}$ and the deposited B-C barrier.
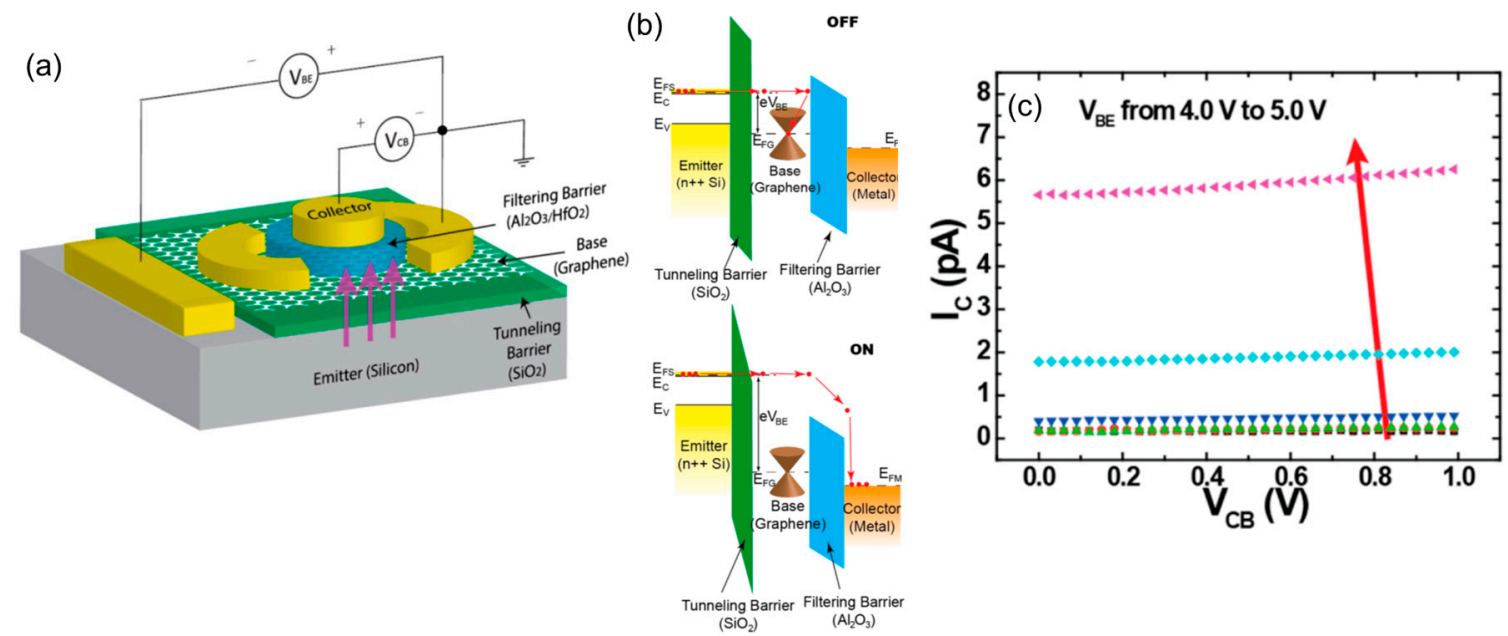

Figure 8. (a) Schematic illustration of a $\mathrm{Si} / \mathrm{SiO}_{2} / \mathrm{Gr} / \mathrm{Al}_{2} \mathrm{O}_{3} / \mathrm{Ti}$ Gr-based hot electron transistor (HET) (GBHET) biased in the common base configuration; (b) band diagrams in the OFF and in the ON state; and (c) output characteristics $\mathrm{I}_{\mathrm{C}}-\mathrm{V}_{\mathrm{CB}}$ of the device. Figures adapted from [23].

Besides Gr, monolayer $\mathrm{MoS}_{2}$ has been also considered as the base material. As an example, Torres et al. [25] demonstrated an HET device based on a stack of ITO/ $\mathrm{HfO}_{2} / \mathrm{MoS}_{2} / \mathrm{SiO}_{2} / \mathrm{n}^{+}-\mathrm{Si}$, where the $n^{+}$-doped $\mathrm{Si}$ substrate worked as the emitter, thermally-grown $\mathrm{SiO}_{2}(3 \mathrm{~nm})$ as the E-B tunneling barrier, a monolayer of CVD-grown $\mathrm{MoS}_{2}$ as the base, the $\mathrm{HfO}_{2}$ layer ( $55 \mathrm{~nm}$ thick) as the B-C barrier and the topmost ITO as the collector electrode. This device showed an improved value of $\alpha \approx 0.95$ with respect to the previously described Gr-base HET prototypes, mainly due to the lower conduction band offset between $\mathrm{MoS}_{2}$ and $\mathrm{HfO}_{2}(1.52 \mathrm{eV})$, with respect to the cases of $\mathrm{Gr} / \mathrm{HfO}_{2}$ $(2.05 \mathrm{eV})$ and $\mathrm{Gr} / \mathrm{Al}_{2} \mathrm{O}_{3}(3.3 \mathrm{eV})$. In spite of this, the collector current density of these devices was still poor (in the order of $\mu \mathrm{A} / \mathrm{cm}^{2}$ ), due to the high E-B barrier between $\mathrm{Si}$ and $\mathrm{SiO}_{2}$.

The above discussed attempts to implement the GBHET device using $\mathrm{Si}$ as the emitter material have been mainly motivated by the perspective of integrating this new technology with the state-of-the-art CMOS fabrication platform. More recently, the possibility of demonstrating GBHETs by the integration of $\mathrm{Gr}$ with nitride semiconductors has been investigated. GaN/AlGaN or GaN/AlN heterostructures are excellent systems to be used as emitter/emitter-base barriers, due to the presence of high density 2DEG at the interface and to the high structural quality of the barrier layer. Thermionic emission has been demonstrated as the main current transport mechanisms in GaN/AlGaN/Gr systems with a thick ( 20 nm) AlGaN barrier layer [100-102].Very efficient current injection by FN tunneling has been recently shown in the case of GaN/AlN/Gr heterojunctions with an ultra-thin (3 nm) AlN barrier [103].

Figure 9a,b illustrates a cross-sectional schematic and the band diagram of a recently-demonstrated GBHET based on a GaN/AlN/Gr/WSe $/$ / Au stack [103]. The 3-nm AlN tunneling barrier was grown on top of a bulk GaN substrate ( $\mathrm{n}^{+}$-doped), working as the emitter. In order to circumvent the problems related to the poor interface quality between $\mathrm{Gr}$ and conventional insulators or semiconductors deposited on top of it, an exfoliated WSe ${ }_{2}$ layer (forming a vdW heterojunction with $\mathrm{Gr}$ ) was adopted as the B-C barrier layer. The resulting $\mathrm{Gr} / \mathrm{WSe}_{2}$ Schottky junction is characterized by a low barrier height due the small band offset $(\sim 0.54 \mathrm{eV})$ between $\mathrm{Gr}$ and $\mathrm{WSe}_{2}$. Figure 9c shows the common-base output characteristics $\left(\mathrm{I}_{\mathrm{C}}-\mathrm{V}_{\mathrm{CB}}\right)$ for different values of the emitter injection current $\mathrm{I}_{\mathrm{E}}$ in the case of a GBHET with a $2.6 \mathrm{~nm}$-thick $\mathrm{WSe}_{2}$ barrier. Furthermore, Figure 9d plots the common-base current transfer ratio 
$\alpha=\mathrm{I}_{\mathrm{C}} / \mathrm{I}_{\mathrm{E}}$ as a function of $\mathrm{V}_{\mathrm{CB}}$ in the same bias range. Three current transport regimes can be identified in Figure $9 \mathrm{c}$, $\mathrm{d}$. At intermediate $\mathrm{V}_{\mathrm{CB}}$ bias (Region II), $\mathrm{I}_{\mathrm{C}}$ is almost independent of the $\mathrm{V}_{\mathrm{CB}}$ and $\alpha \approx 1$, indicating that almost all the injected hot electrons are able to overcome the Gr/WSe $\mathrm{W}_{2}$ Schottky barrier and reach the collector. For $\mathrm{V}_{\mathrm{CB}}<0$ (Region I), the injected electrons from the emitter are reflected back by the elevated $B-C$ potential barrier, resulting in a reduced $\mathrm{I}_{C}$ and $\alpha<1$. Finally, at higher positive $\mathrm{V}_{\mathrm{CB}}$, current starts to increase due to the increasing contribution of cold electrons' leakage current from the base. Although this device showed excellent DC characteristics in terms of $\alpha$, its operating $\mathrm{V}_{\mathrm{BC}}$ window was very limited $(\sim 0.3 \mathrm{~V})$, due to the poor blocking capability of the B-C junction with an ultrathin $\mathrm{WSe}_{2}$ barrier. Increasing the $\mathrm{WSe}_{2}$ thickness improved the blocking capability of the B-C barrier, but resulted in a reduced value of $\alpha$. As an example, $\alpha=0.75$ was evaluated for a GaN/AlN/Gr/WSe $2 / \mathrm{Au}$ GBHET with a $10 \mathrm{~nm}$-thick $\mathrm{WSe}_{2}$ barrier [103].
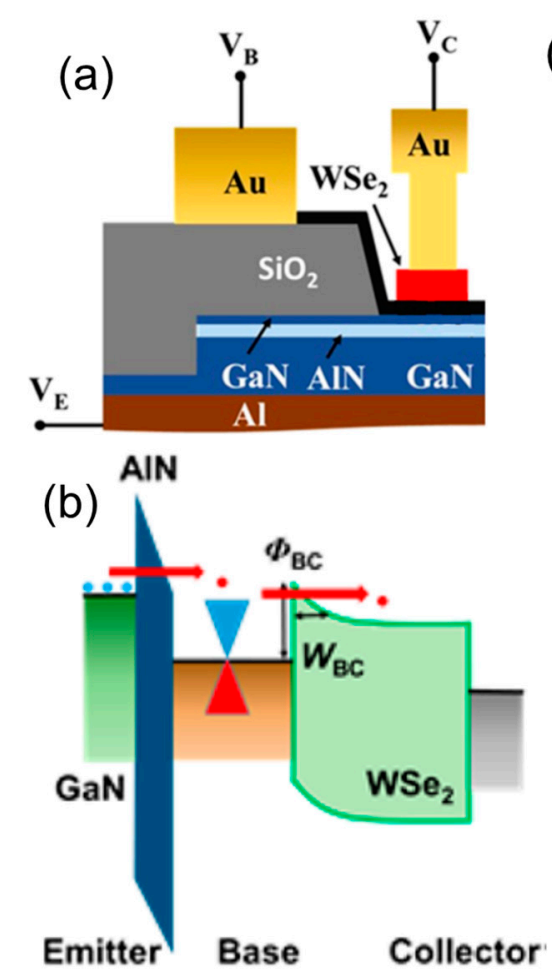

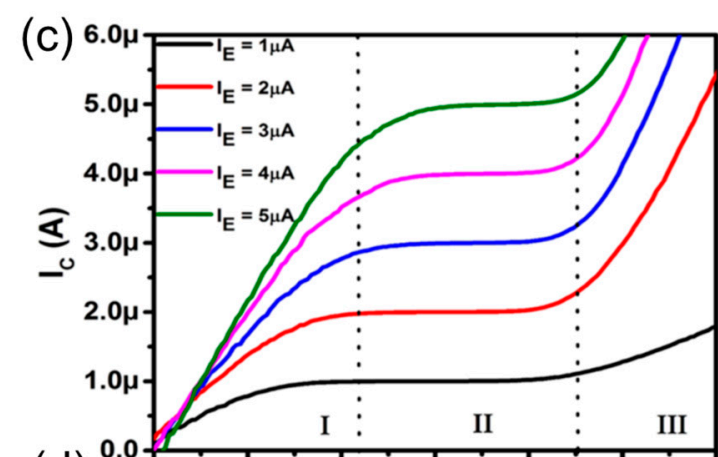

(d)

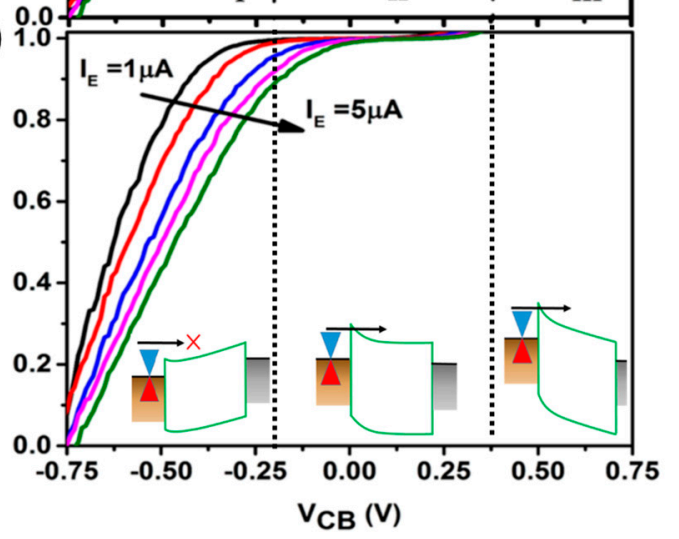

Figure 9. (a) Cross-section schematic and (b) band diagram of a GBHET based on the $\mathrm{GaN} / \mathrm{AlN} / \mathrm{Gr} / \mathrm{WSe}_{2} / \mathrm{Au}$ stack; (c) common-base output characteristics $\left(\mathrm{I}_{\mathrm{C}}-\mathrm{V}_{\mathrm{CB}}\right)$ for different values of the emitter injection current $\mathrm{I}_{\mathrm{E}}$ in the case of a GBHET with a $2.6 \mathrm{~nm}$-thick WSe $\mathrm{W}_{2}$ barrier; (d) plots of $\alpha=\mathrm{I}_{\mathrm{C}} / \mathrm{I}_{\mathrm{E}}$ as a function of $\mathrm{V}_{\mathrm{CB}}$ in the same bias range. Images adapted with permission from [103].

Table 1 reports a comparison of the main DC electrical parameters (i.e., the collector current density $\mathrm{J}_{\mathrm{C}}$, the common-base current transfer ratio $\alpha$ and the common-emitter current gain $\beta$ ) for the HETs with a Gr or $\mathrm{MoS}_{2}$ base reported in the literature. Some examples of HETs fully based on nitride-semiconductors with a sub-10-nm base thickness are reported for comparison. In spite of the theoretically-predicted superior performances (related to ballistic transport in the atomically-thin $\mathrm{Gr}$ base), GBHETs still suffer from reduced values of $J_{C}, \alpha$ and $\beta$ with respect to HETs fabricated by bandgap engineering of III-N semiconductors (even with a thicker GaN base). This reduced GBHET performance can be due to the non-ideal quality of Gr interfaces with the emitter and collector barriers, indicating that further work will be necessary in this direction. 
Table 1. Comparison of $\mathrm{J}_{C}, \alpha$ and $\beta$ for the-state-of-the-art HETs with a Gr or $\mathrm{MoS}_{2}$ base and for nitride semiconductor-based HETs with a sub-10-nm base thickness

\begin{tabular}{ccccccc}
\hline Emitter/Emitter-Base Barrier & Base (Thickness) & Base-Collector Barrier & $\mathbf{J}_{\mathbf{C}} \mathbf{~ ( A / \mathbf { c m } ^ { 2 } )}$ & $\alpha$ & $\beta$ & Reference \\
\hline $\mathrm{Si} / \mathrm{SiO}_{2}$ & $\mathrm{Gr}(0.35 \mathrm{~nm})$ & $\mathrm{Al}_{2} \mathrm{O}_{3}$ & $\sim 1 \times 10^{-5}$ & $\sim 0.06$ & $\sim 0.06$ & {$[22]$} \\
$\mathrm{S} / \mathrm{SiO}_{2}$ & $\mathrm{Gr}(0.35 \mathrm{~nm})$ & $\mathrm{Al}_{2} \mathrm{O}_{3}, \mathrm{HfO}_{2}$ & $\sim 5 \times 10^{-5}$ & $\sim 0.44$ & $\sim 0.78$ & {$[23]$} \\
$\mathrm{Gi} / \mathrm{TmSiO} / \mathrm{TiO}_{2}$ & $\mathrm{Gr}(0.35 \mathrm{~nm})$ & $\mathrm{Si}$ & $\sim 4$ & $\sim 0.28$ & $\sim 0.4$ & {$[99]$} \\
$\mathrm{GaN} / \mathrm{AlN}$ & $\mathrm{Gr}(0.35 \mathrm{~nm})$ & $\mathrm{WSe}_{2}(10 \mathrm{~nm})$ & $\sim 50$ & $\sim 0.75$ & $4-6$ & {$[103]$} \\
$\mathrm{Si} / \mathrm{SiO}_{2}$ & $\mathrm{MoS}_{2}(0.7 \mathrm{~nm})$ & $\mathrm{HfO}_{2}$ & $\sim 1 \times 10^{-6}$ & $\sim 0.95$ & $\sim 4$ & {$[25]$} \\
$\mathrm{GaN} / \mathrm{Al}_{0.24} \mathrm{Ga}_{0.76} \mathrm{~N}$ & $\mathrm{GaN}(10 \mathrm{~nm})$ & $\mathrm{Al}_{0.08} \mathrm{Ga}_{0.92} \mathrm{~N}$ & $\sim 5 \times 10^{3}$ & $\sim 0.97$ & $\sim 1$ & {$[95]$} \\
$\mathrm{GaN} / \mathrm{AlN}$ & $\mathrm{GaN} / \mathrm{InGaN}(7 \mathrm{~nm})$ & $\mathrm{GaN}$ & $\sim 2.5 \times 10^{3}$ & $>0.5$ & $>1$ & {$[97]$} \\
$\mathrm{GaN} / \mathrm{AlN}$ & $\mathrm{GaN}(8 \mathrm{~nm})$ & $\mathrm{AlGaN} / \mathrm{GaN}$ & $\sim 46 \times 10^{3}$ & $\sim 0.93$ & $\sim 14.5$ & {$[96]$} \\
\hline
\end{tabular}

\section{Materials Science Issues and Challenges}

The device structures reviewed in this paper are based on vdW heterostructures of 2D materials (Gr, TMDs, h-BN) [15] or on mixed-dimensional vdW heterostructures [17] formed by the integration of 2D materials with 3D semiconductors and insulators (bulk or thin films). In many cases, proof of concept devices have been fabricated by the transfer of the individual 2D components, obtained by mechanical or chemical exfoliation of flakes from layered bulk crystals. As a matter of fact, the large area growth method of electronic quality 2D materials and heterostructures are mandatory to move from proof-of-concept devices to industrial applications.

Nowadays, high quality Gr can be grown on a large area by CVD on catalytic metals, such as copper [42], followed by transfer to arbitrary substrates [104]. Although this is a very versatile and widely-used method, it suffers from some drawbacks related to Gr damage and polymer contaminations during the transfer procedure, as well as of possible adhesion problems between $\mathrm{Gr}$ and the substrate. Furthermore, it typically introduces undesired metal $(\mathrm{Cu}, \mathrm{Fe})$ contaminations [105] originating from the growth substrate and the typically used $\mathrm{Cu}$ etchants. An intense research activity is still in progress to optimize $\mathrm{Gr}$ transfer procedures to minimize $\mathrm{Gr}$ defectivity and contaminations associated with Gr manipulation [106-109].

Notwithstanding the above-mentioned issues, large area $\left(\mathrm{cm}^{2}\right)$ Gr heterojunctions with semiconductors are currently fabricated by optimized transfer of CVD-grown Gr. These have been used for the fabrication of device arrays using semiconductor fab-compatible approaches. As an example, Gr junctions with $\mathrm{AlGaN} / \mathrm{GaN}$ heterostructures showing excellent lateral uniformity have been reported $[100,110]$ and are currently investigated as building blocks for HET devices. Figure 10a,b reports two representative morphologies of the $\mathrm{AlGaN}$ surface without (a) and with (b) a single-layer $\mathrm{Gr}$ membrane on top. Figure 10c,d shows two arrays of local current-voltage characteristics measured by conductive atomic force microscopy (CAFM) at the different positions on bare AlGaN- and Gr-coated AlGaN, respectively. In both cases, all the I-V curves exhibit a rectifying behavior, with a lower Schottky barrier height for the Gr/AlGaN junction. Noteworthy, a very narrow spread between different curves is observed for the $\mathrm{Gr} / \mathrm{AlGaN}$ junction, indicating an excellent lateral homogeneity of the Gr/AlGaN Schottky contact.

Under many respects, the direct growth/deposition of Gr on the target substrate would be highly desirable. However, to date, high quality Gr growth has been demonstrated only on a few semiconducting or semi-insulating materials, such as silicon-carbide [38-40,111,112] and, more recently, germanium [113]. Single or few layers of $\mathrm{Gr}$ can be obtained on the Si face (0001) of hexagonal SiC, either by controlled sublimation of Si at high temperatures (typically $>1650^{\circ} \mathrm{C}$ ) in Ar at atmospheric pressure or by direct CVD deposition at lower temperatures $\left(\sim 1450{ }^{\circ} \mathrm{C}\right)$ using an external carbon source (such as $\mathrm{C}_{3} \mathrm{H}_{8}$ ) with $\mathrm{H}_{2}$ or $\mathrm{H}_{2} / \mathrm{Ar}$ carrier gases [111]. Gr grown on $\mathrm{SiC}(0001)$, commonly named epitaxial graphene (EG), generally exhibits a precise epitaxial orientation with respect to the substrate, which originates from the peculiar nature of the interface, i.e., the presence of a carbon buffer layer with mixed $\mathrm{sp}^{2} / \mathrm{sp}^{3}$ hybridization sharing covalent bonds with the Si face of SiC [114,115]. This buffer layer has a strong impact both on the lateral (i.e., in plane) current transport in EG, causing a reduced carrier mobility, and on the vertical current transport at the EG/SiC interface [116,117]. 
Hydrogen intercalation at the interface between the buffer layer and Si face has been demonstrated to be efficient in increasing Gr carrier mobility and tuning the Schottky barrier and, hence, the vertical current transport across the $\mathrm{Gr} / \mathrm{SiC}$ interface [118]. Recently, CVD growth of $\mathrm{Gr}$ from carbon precursors on nitride semiconductor (AlN) substrates/templates has been also investigated. Gr deposition on these non-catalytic surfaces represents a challenging task, as it requires significantly higher temperatures as compared to conventional deposition on metals. The first experimental works addressing this issue showed the possibility of depositing a few layers of Gr both on bulk AlN (Al and N face) and on AlN templates grown on different substrates, such as $\mathrm{Si}(111)$ and $\mathrm{SiC}$, at temperatures $>1250{ }^{\circ} \mathrm{C}$ using propane $\left(\mathrm{C}_{3} \mathrm{H}_{8}\right)$ as the carbon source, without significantly degrading the morphology of AlN substrates/templates $[119,120]$. In spite of the very promising results of these experiments, further work will be required to evaluate the feasibility and the effects of CVD Gr growth onto AlN/GaN or AlGaN/GaN heterostructures. Moreover, the possibility of integrating these high temperature processes in the fabrication flow of GBHETs with the GaN/AlN (or GaN/AlGaN) emitter needs to be investigated.

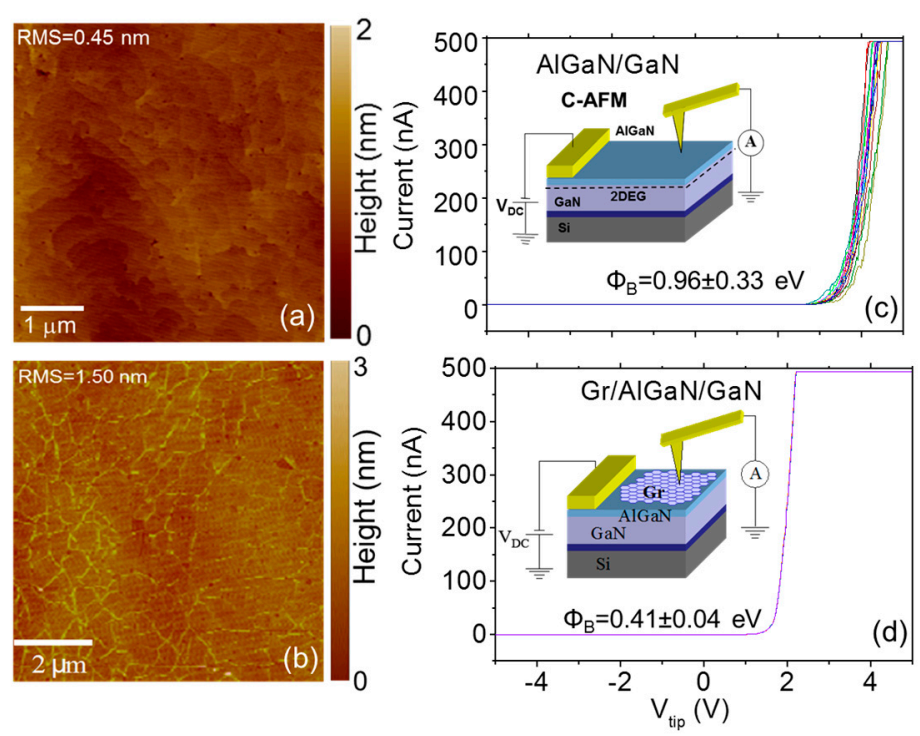

Figure 10. AFM morphologies of an AlGaN/GaN heterostructure (a) and of Gr transferred onto $\mathrm{AlGaN} / \mathrm{GaN}(\mathbf{b})$. Current-voltage characteristics measured by conductive atomic force microscopy (CAFM) on an array of different positions on the bare AlGaN surface (c) and on the Gr-coated AlGaN surface (d). Figures adapted with permission from [100].

Although most of TMD-based devices are still fabricated using exfoliated flakes, much progress has been made in the last few years in the CVD deposition of $\mathrm{MoS}_{2}$ and other TMDs, both on insulating substrates, such as $\mathrm{SiO}_{2}$ [121,122] and sapphire [123], and on semiconductors, such as GaN [124]. Noteworthy, an epitaxial registry with the substrate has been observed for CVD-grown $\mathrm{MoS}_{2}$ on sapphire and on GaN.

High quality thin insulating layers are key components for most of the above-discussed lateral and vertical devices based on Gr and TMDs. In this context, due to the layer-by-layer deposition mechanism, atomic layer deposition (ALD) has been considered as method of choice to grow thin high- $\mathrm{k}$ dielectrics (such as $\mathrm{Al}_{2} \mathrm{O}_{3}$ and $\mathrm{HfO}_{2}$ ) on $\mathrm{Gr}$ and TMDs [125]. The main challenge related to ALD on the chemically inert and dangling-bonds' free surface of 2D materials is the activation of nucleation sites from which the growth can initiate. Several approaches have been explored so far to this aim, like ex situ deposition of metal or metal-oxide seed layers [126] or pre-functionalization of Gr [127]. Recently, highly uniform $\mathrm{Al}_{2} \mathrm{O}_{3}$ films with very low leakage current and a high breakdown field have been deposited on Gr by a two-step thermal ALD process, resulting in minimal degradation of the $\mathrm{Gr}$ electronic/structural properties [128]. As a matter of fact, the interface between Gr and TMDs with 
common insulators is not atomically flat. Furthermore, interface or near-interface defects are typically present in the oxide and act as trapping states for electrons/holes.

In this respect, due to its atomically-flat crystal surface, excellent insulating properties and chemical inertness, h-BN represents an ideal ultra-flat substrate and interlayer dielectric for $\mathrm{Gr}$ (to which it is closely lattice matched, within 1.6\%) and, by extension, other 2D semiconductor materials [3]. Although single and multilayer h-BN used for device demonstration are still mainly obtained by exfoliation from the bulk crystal, significant progress has been also made towards the controlled synthesis of large-area, high-quality h-BN films by CVD on metal catalysts, such as Ni [129], $\mathrm{Cu}$ [130] and Ni/Cu alloys [131]. Recently, Sonde et al. reported a detailed study clarifying the mechanisms of CVD h-BN growth on $\mathrm{Ni}$ and $\mathrm{Co}$ thin films on $\mathrm{SiO}_{2} / \mathrm{Si}$ substrates [132], which could lead to large area (up to wafer scale) growth of h-BN thin films on arbitrary substrates in a transfer-free manner. As schematically illustrated in Figure 11a, after exposure to ammonia $\left(\mathrm{NH}_{3}\right)$ and diborane $\left(\mathrm{B}_{2} \mathrm{H}_{6}\right)$ precursors at high temperature $\left(\sim 1050^{\circ} \mathrm{C}\right)$, diffusion of boron $(\mathrm{B})$ and nitrogen $(\mathrm{N})$ in Ni occurs, followed by segregation/precipitation of h-BN multilayers both on the upper and the buried face of the Ni film. These h-BN films showed excellent insulating properties, with a breakdown field of $9.34 \mathrm{MV} \cdot \mathrm{cm}^{-1}$, as determined from current-voltage characteristics measured by CAFM (see Figure 11b). Finally, the quality of h-BN as a substrate for back-gated Gr field effect transistors has been evaluated. The Gr resistance measured under forward and backward gate bias sweep is reported in Figure 11c, showing minimal hysteresis associated with the absence of charge trapping at the $\mathrm{Gr} / \mathrm{h}-\mathrm{BN}$ interface.

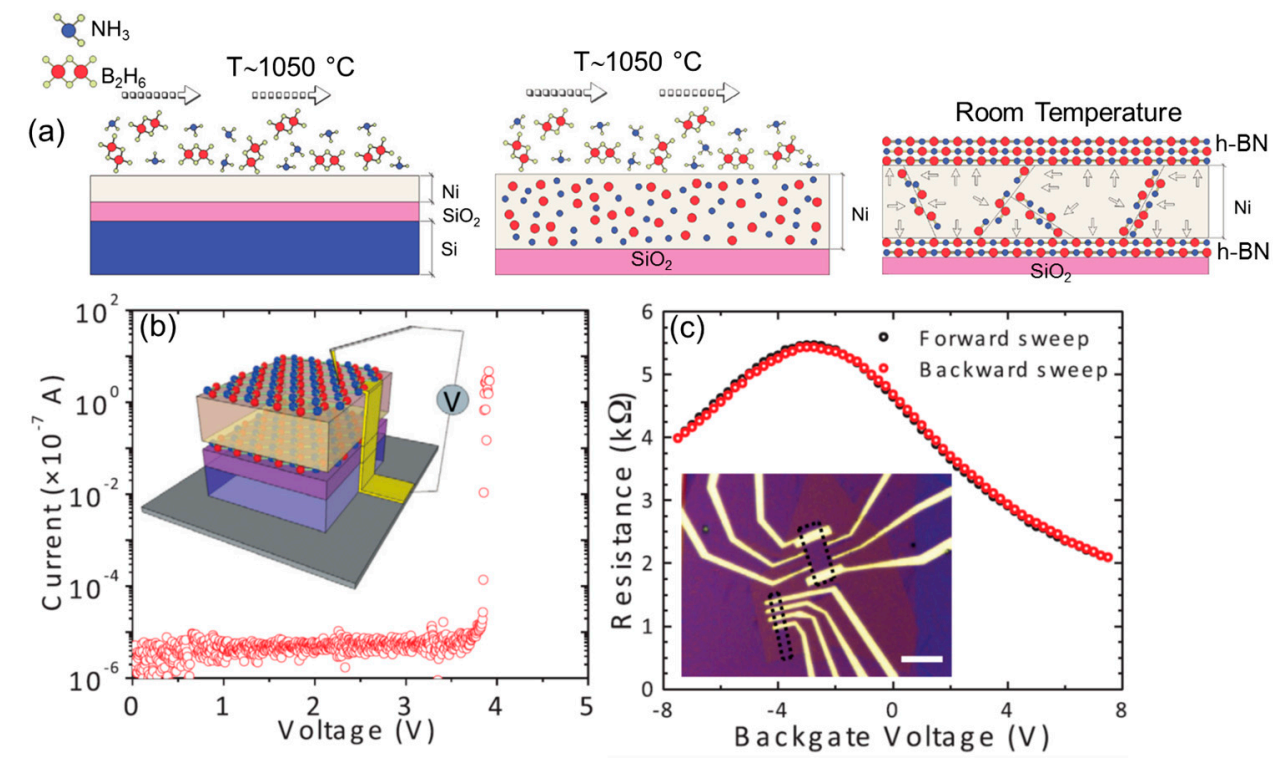

Figure 11. (a) Schematic illustration of the mechanism of h-BN CVD growth on Ni thin films by ammonia $\left(\mathrm{NH}_{3}\right)$ and diborane $\left(\mathrm{B}_{2} \mathrm{H}_{6}\right)$ precursors at high temperature $\left(\sim 1050{ }^{\circ} \mathrm{C}\right)$; $(\mathbf{b})$ estimation of the breakdown field $\left(9.34 \mathrm{MV} \cdot \mathrm{cm}^{-1}\right)$ of the multilayer h-BN (10-11 layers) by current-voltage measurements with CAFM; (c) resistance of a Gr field effect transistor with an h-BN back-gate, showing minimal hysteresis between forward and backward gate bias sweep. Figures adapted with permission from [132].

PMMA-assisted transfer is the simplest way to construct arbitrary 2D heterostructures. However, the quality of the interface can be affected by the trapping of polymer, solvents or chemicals used for transfer. This represents a major issue, especially for large-area 2D heterostructures. In this respect, the direct synthesis of vertically-stacked 2D heterojunctions, obtained by CVD growth of one 2D material on another, would be highly desirable, as the direct growth would result, in principle, in clean heterojunction interfaces. The early van der Waals epitaxy experiments started from Gr and h-BN, which share a similar lattice constant. Yang et al. reported a plasma-assisted deposition method for 
the growth of single domain Gr on the h-BN substrate [133]. Gr grows with a preferred orientation with respect to the h-BN lattice, and the size of the domain is only restricted by the area of underlying h-BN. Furthermore, Shi et al. have obtained a vertically-stacked $\mathrm{MoS}_{2} / \mathrm{Gr}$ heterostructure via thermal decomposition of ammonium thiomolybdate precursors on $\mathrm{Gr}$ surfaces [134]. In spite of the $28 \%$ mismatch between $\mathrm{MoS}_{2}$ and $\mathrm{Gr}$ lattice constants, $\mathrm{Gr}$ is still a good growth platform for $\mathrm{MoS}_{2}$, as the growth of $\mathrm{MoS}_{2}$ on $\mathrm{Gr}$ involves strain to accommodate the lattice mismatch. Lin et al. demonstrated the direct growth of $\mathrm{MoS}_{2}, \mathrm{WSe}_{2}$ and h-BN on epitaxial Gr on SiC through CVD methods [135], showing how the morphology of the underlying Gr strongly affects the growth and the properties of top heterostructures. In particular, strain, wrinkling and defects on the surface of Gr provide the nucleation centers for the upper layer material growth.

\section{Summary and Outlook}

We have reviewed the state-of-the-art of 2D material-based vertical transistors for logic and high frequency electronics.

Regarding logic applications, vdW heterostructures obtained by 2D/2D or 2D/3D material stacking have been explored by several research groups as a platform to implement tunneling field effect transistors (TFETs). Resonant TFETs have been demonstrated by rotationally-aligned Gr monolayers or bilayers separated by a tunnel barrier (h-BN or TMD). However, although these prototypes permitted exploring interesting physical phenomena, the possibility of realizing vdW heterostructures with a precise crystallographic alignment on a large area represents a big challenge, making real applications of resonant TFETs in the near future difficult. On the other hand, TFETs relying on the band-to-band-tunneling across the interface of different semiconducting layered materials could have more realistic prospects of practical applications, once further progress in van der Waals epitaxy of TMDs is achieved.

Regarding high frequency applications of 2D materials, lateral Gr FETs with a very high cut-off frequency $\left(f_{T}>400 \mathrm{GHz}\right)$ have been demonstrated, exploiting the high $\mathrm{Gr}$ channel mobility. However, these devices suffer from a lower maximum oscillation frequency $f_{M A X}$, due to the poor saturation of the output characteristics mainly originating from the missing bandgap of Gr. Vertical transistors based on 2D/2D or 2D/3D material heterostructures can represent an alternative to lateral Gr FETs to realize RF functions. In particular, the hot electrons transistor (HET) has been theoretically predicted to be suitable for ultra-high-frequency applications, with $f_{T}$ and $f_{M A X}$ values in the $\mathrm{THz}$ range. The main requirement for the implementation of this device concept, i.e., an ultrathin base allowing both ballistic transport in the vertical direction and low base resistance in the lateral direction, can be fulfilled by 2D materials, in particular Gr. However, although much progress has been made in the last few years in the fabrication of Gr-based HETs, the electrical performances of these demonstrators are still lower than those of previously-reported HET devices fabricated with III-V heterostructures (even with a thicker base) and far from the state-of-the-art RF HEMTs (which represent the benchmark for any competing RF device concept). Further improvements in the emitter-base and base-collector barrier layers and interfaces are still required to achieve the theoretical DC and RF performances of HETs.

Generally speaking, the perspective of industrial applications of 2D material-based devices is strongly related to the possibility of growing individual 2D layers and, possibly, vdW heterostructures on a large area.

Acknowledgments: The authors want to acknowledge all of the following colleagues for useful discussions and participation in the experiments: Gabriele Fisichella., Emanuela Schilirò, Salvatore Di Franco, Patrick Fiorenza, Raffaella Lo Nigro, Ioannis Deretzis, Antonino La Magna, Giuseppe Nicotra, Corrado Bongiorno, Corrado Spinella (CNR-Institute for Microelectronics and Microsystems (CNR-IMM), Catania, Italy); Sebastiano Ravesi, Stella Lo Verso, Ferdinando Iucolano (STMicroelectronics, Catania, Italy); Eric Frayssinet, Roy Dagher, Adrien Michon, Yvon Cordier (CNRS-Centre de Recherche sur l'Hétéro-Epitaxie et ses Applications (CNRS-CRHEA), Valbonne, France); Mike Leszczynski, Piotr Kruszewski, Pawel Prystawko (TopGaN, Warsaw, Poland); Rositza Yakimova, Anelia Kakanakova (Linkoping University, Linkoping, Sweden); Bela Pecz (Institute for Technical Physics and Materials Science Research, Centre for Energy Research, Hungarian Academy of Science, 
Budapest, Hungary); and Luigi Colombo (Texas Instruments, Texas, TX, USA). This paper has been supported, in part, by the Flag-ERA project "GraNitE: Graphene heterostructures with Nitrides for high frequency Electronics".

Conflicts of Interest: The authors declare no conflict of interest.

\section{References}

1. Novoselov, K.S.; Geim, A.K.; Morozov, S.V.; Jiang, D.; Zhang, Y.; Dubonos, S.V.; Grigorieva, I.V.; Firsov, A.A. Electric Field Effect in Atomically Thin Carbon Films. Science 2004, 306, 666-669. [CrossRef] [PubMed]

2. Bolotin, K.I.; Sikes, K.J.; Hone, J.H.; Stormer, L.; Kim, P. Temperature-Dependent Transport in Suspended Graphene. Phys. Rev. Lett. 2008, 101, 096802. [CrossRef] [PubMed]

3. Dean, C.R.; Young, A.F.; Meric, I.; Lee, C.; Wang, L.; Sorgenfrei, S.; Watanabe, K.; Taniguchi, T.; Kim, P.; Shepard, K.L.; et al. Boron nitride substrates for high-quality graphene electronics. Nat. Nanotechnol. 2010, 5, 722-726. [CrossRef] [PubMed]

4. Mayorov, A.S.; Gorbachev, R.V.; Morozov, S.V.; Britnell, L.; Jalil, R.; Ponomarenko, L.A.; Blake, P.; Novoselov, K.S.; Watanabe, K.; Taniguchi, T.; et al. Micrometer-scale ballistic transport in encapsulated graphene at room temperature. Nano Lett. 2011, 11, 2396-2399. [CrossRef] [PubMed]

5. Giannazzo, F.; Raineri, V. Graphene: Synthesis and nanoscale characterization of electronic properties. Rivista del Nuovo Cimento 2012, 35, 267-304.

6. Sonde, S.; Giannazzo, F.; Vecchio, C.; Yakimova, R.; Rimini, E.; Raineri, V. Role of graphene/substrate interface on the local transport properties of the two-dimensional electron gas. Appl. Phys. Lett. 2010, 97, 132101. [CrossRef]

7. Giannazzo, F.; Sonde, S.; Lo Nigro, R.; Rimini, E.; Raineri, V. Mapping the Density of Scattering Centers Limiting the Electron Mean Free Path in Graphene. Nano Lett. 2011, 11, 4612-4618. [CrossRef] [PubMed]

8. Lemme, M.C.; Echtermeyer, T.J.; Baus, M.; Kurz, H. A Graphene Field-Effect Device. IEEE Electron Device Lett. 2007, 28, 282-284. [CrossRef]

9. Schwierz, F. Graphene transistors. Nat. Nanotechnol. 2010, 5, 487-496. [CrossRef] [PubMed]

10. Liao, L.; Duan, X. Graphene for radio frequency electronics. Mater. Today 2012, 15, 328-338. [CrossRef]

11. Cheng, R.; Bai, J.; Liao, L.; Zhou, H.; Chen, Y.; Liu, L.; Lin, Y.-C.; Jiang, S.; Huang, Y.; Duan, X. High-frequency self-aligned graphene transistors with transferred gate stacks. Proc. Natl. Acad. Sci. USA 2012, 109, 11588-11592. [CrossRef] [PubMed]

12. Wang, H.; Hsu, A.; Wu, J.; Kong, J.; Palacios, T. Graphene-Based Ambipolar RF Mixers. IEEE Electron Device Lett. 2010, 31, 906-908. [CrossRef]

13. Wang, Q.H.; Zadeh, K.K.; Kis, A.; Coleman, J.N.; Strano, M.S. Electronics and optoelectronics of two-dimensional transition metal dichalcogenides. Nat. Nanotechnol. 2012, 7, 699-712. [CrossRef] [PubMed]

14. Liu, H.; Neal, A.T.; Zhu, Z.; Luo, Z.; Xu, X.; Tománek, D.; Ye, P.D. Phosphorene: An Unexplored 2D Semiconductor with a High Hole Mobility. ACS Nano 2014, 8, 4033-4041. [CrossRef] [PubMed]

15. Geim, A.K.; Grigorieva, I.V. Van der Waals heterostructures. Nature 2013, 499, 419-425. [CrossRef] [PubMed]

16. Wang, H.; Liu, F.; Fu, W.; Fang, Z.; Zhoue, W.; Liu, Z. Two-dimensional heterostructures: Fabrication, characterization, and application. Nanoscale 2014, 6, 12250-12272. [CrossRef] [PubMed]

17. Jariwala, D.; Marks, T.J.; Hersam, M.C. Mixed-dimensional van der Waals heterostructures. Nat. Mater. 2017, 16, 170-181. [CrossRef] [PubMed]

18. Britnell, L.; Gorbachev, R.V.; Jalil, R.; Belle, B.D.; Schedin, F.; Mishchenko, A.; Georgiou, T.; Katsnelson, M.I.; Eaves, L.; Morozov, S.V.; et al. Field-Effect Tunneling Transistor Based on Vertical Graphene Heterostructures. Science 2012, 335, 947-950. [CrossRef] [PubMed]

19. Georgiou, T.; Jalil, R.; Belle, B.D.; Britnell, L.; Gorbachev, R.V.; Morozov, S.V.; Kim, Y.-J.; Gholinia, A.; Haigh, S.J.; Makarovsky, O.; et al. Vertical field-effect transistor based on graphene-WS $\mathrm{W}_{2}$ heterostructures for flexible and transparent electronics. Nat. Nanotechnol. 2013, 8, 100-103. [CrossRef] [PubMed]

20. Sarkar, D.; Xie, X.; Liu, W.; Cao, W.; Kang, J.; Gong, Y.; Kraemer, S.; Ajayan, P.M.; Banerjee, K. A subthermionic tunnel field-effect transistor with an atomically thin channel. Nature 2015, 526, 91-95. [CrossRef] [PubMed]

21. Yang, H.; Heo, J.; Park, S.; Song, H.J.; Seo, D.H.; Byun, K.-E.; Kim, P.; Yoo, I.; Chung, H.-J.; Kim, K. Graphene barristor, a triode device with a gate-controlled Schottky barrier. Science 2012, 336, 1140-1143. [CrossRef] [PubMed] 
22. Vaziri, S.; Lupina, G.; Henkel, C.; Smith, A.D.; Ostling, M.; Dabrowski, J.; Lippert, G.; Mehr, W.; Lemme, M.C. A graphene-based hot electron transistor. Nano Lett. 2013, 13, 1435-1439. [CrossRef] [PubMed]

23. Zeng, C.; Song, E.B.; Wang, M.; Lee, S.; Torres, C.M.; Tang, J.; Weiller, B.H.; Wang, K.L. Vertical graphene-base hot electron transistor. Nano Lett. 2013, 13, 2370-2375. [CrossRef] [PubMed]

24. Vaziri, S.; Smith, A.D.; Östling, M.; Lupina, G.; Dabrowski, J.; Lippert, G.; Mehr, W.; Driussi, F.; Venica, S.; Di Lecce, V.; et al. Going ballistic: Graphene hot electron transistors. Solid State Commun. 2015, 224, 64-75. [CrossRef]

25. Torres, C.M.; Lan, Y.W.; Zeng, C.; Chen, J.H.; Kou, X.; Navabi, A.; Tang, J.; Montazeri, M.; Adleman, J.R.; Lerner, M.B.; et al. High-Current Gain Two-Dimensional $\mathrm{MoS}_{2}$-Base Hot-Electron Transistors. Nano Lett. 2015, 15, 7905-7912. [CrossRef] [PubMed]

26. Radisavljevic, B.; Radenovic, A.; Brivio, J.; Giacometti, V.; Kis, A. Single-layer $\mathrm{MoS}_{2}$ transistors. Nat. Nanotechnol. 2011, 6, 147-150. [CrossRef] [PubMed]

27. Kaasbjerg, K.; Thygesen, K.S.; Jacobsen, K.W. Phonon-limited mobility in n-type single-layer $\mathrm{MoS}_{2}$ from first principles. Phys. Rev. B 2012, 85, 115317. [CrossRef]

28. Radisavljevic, B.; Kis, A. Mobility engineering and a metal-insulator transition in monolayer $\mathrm{MoS}_{2}$. Nat. Mater. 2013, 12, 815-820. [CrossRef] [PubMed]

29. Fuhrer, M.S.; Hone, J. Measurement of mobility in dual-gate $\mathrm{MoS}_{2}$ transistor. Nat. Nanotechnol. 2013, 8 , 146-147. [CrossRef] [PubMed]

30. Li, L.; Yu, Y.; Ye, G.J.; Ge, Q.; Ou, X.; Wu, H.; Feng, D.; Chen, X.H.; Zhang, Y. Black phosphorus field-effect transistors. Nat. Nanotechnol. 2014, 9, 372-377. [CrossRef] [PubMed]

31. Yoon, Y.; Ganapathi, K.; Salahuddin, S. How good can monolayer $\mathrm{MoS}_{2}$ transistors be? Nano Lett. 2011, 11, 3768-3773. [CrossRef] [PubMed]

32. Alam, K.; Lake, R. Monolayer $\mathrm{MoS}_{2}$ transistors beyond the technology road map. IEEE Trans. Electron Devices 2012, 59, 3250-3254. [CrossRef]

33. Liu, L.; Lu, Y.; Guo, J. On monolayer $\mathrm{MoS}_{2}$ field-effect transistors at the scaling limit. IEEE Trans. Electron Devices 2013, 60, 4133-4139. [CrossRef]

34. Majumdar, K.; Hobbs, C.; Kirsch, P.D. Benchmarking transition metal dichalcogenide MOSFET in the ultimate physical scaling limit. IEEE Electron Device Lett. 2014, 35, 402-404. [CrossRef]

35. International Technology Roadmap for Semiconductors (ITRS, 2013). Available online: http://www.itrs2.net/ (accessed on 1 December 2017).

36. Desai, S.B.; Madhvapathy, S.R.; Sachid, A.B.; Llinas, J.P.; Wang, Q.; Ahn, G.H.; Pitner, G.; Kim, M.J.; Bokor, J.; $\mathrm{Hu}, \mathrm{C} . ;$ et al. $\mathrm{MoS}_{2}$ transistors with 1-nanometer gate lengths. Science 2016, 354, 99-102. [CrossRef] [PubMed]

37. Meric, I.; Baklitskaya, N.; Kim, P.; Shepard, K.L. RF performance of to p-gated, zero-bandgap graphene field-effect transistors. In Proceedings of the IEEE International Electron Devices Meeting (IEDM 2008), San Francisco, CA, USA, 15-17 December 2008; pp. 1-4.

38. Berger, C.; Song, Z.; Li, X.; Wu, X.; Brown, N.; Naud, C.; Mayou, D.; Li, T.; Hass, J.; Marchenkov, A.N.; et al. Electronic confinement and coherence in patterned epitaxial graphene. Science 2006, 312, 1191-1196. [CrossRef] [PubMed]

39. Emtsev, K.V.; Bostwick, A.; Horn, K.; Jobst, J.; Kellogg, G.L.; Ley, L.; McChesney, J.L.; Ohta, T.; Reshanov, S.A.; Röhrl, J.; et al. Towards wafer-size graphene layers by atmospheric pressure graphitization of silicon carbide. Nat. Mater. 2009, 8, 203-207. [CrossRef] [PubMed]

40. Virojanadara, C.; Syvajarvi, M.; Yakimova, R.; Johansson, L.I.; Zakharov, A.A.; Balasubramanian, T. Homogeneous large-area graphene layer growth on 6H-SiC(0001). Phys. Rev. B 2008, 78, 245403. [CrossRef]

41. Vecchio, C.; Sonde, S.; Bongiorno, C.; Rambach, M.; Yakimova, R.; Rimini, E.; Raineri, V.; Giannazzo, F. Nanoscale structural characterization of epitaxial graphene grown on off-axis $4 \mathrm{H}-\mathrm{SiC}$ (0001). Nanoscale Res. Lett. 2011, 6, 269. [CrossRef] [PubMed]

42. Li, X.; Cai, W.; An, J.; Kim, S.; Nah, J.; Yang, D.; Piner, R.; Velamakanni, A.; Jung, I.; Tutuc, E.; et al. Large-area synthesis of high-quality and uniform graphene films on copper foils. Science 2009, 324, 1312-1314. [CrossRef] [PubMed]

43. Wu, Y.; Jenkins, K.A.; Valdes-Garcia, A.; Farmer, D.B.; Zhu, Y.; Bol, A.A.; Dimitrakopoulos, C.; Zhu, W.; Xia, F.; Avouris, P.; et al. State-of-the-Art Graphene High-Frequency Electronics. Nano Lett. 2012, 12, 3062-3067. [CrossRef] [PubMed] 
44. Lin, Y.M.; Dimitrakopoulos, C.; Jenkins, K.A.; Farmer, D.B.; Chiu, H.Y.; Grill, A.; Avouris, P. 100-GHz transistors from wafer-scale epitaxial graphene. Science 2010, 327, 662. [CrossRef] [PubMed]

45. Li, X.; Mullen, J.T.; Jin, Z.; Borysenko, K.M.; Nardelli, M.B.; Kim, K.W. Intrinsic electrical transport properties of monolayer silicene and $\mathrm{MoS}_{2}$ from first principles. Phys. Rev. B 2013, 87, 115418. [CrossRef]

46. Akinwande, D.; Petrone, N.; Hone, J. Two-dimensional flexible nanoelectronics. Nat. Commun. 2014, 5, 5678. [CrossRef] [PubMed]

47. Cheng, R.; Jian, S.; Chen, Y.; Weiss, N.; Cheng, H.C.; Wu, H.; Huang, Y.; Duan, X. Few-layer molybdenum disulfide transistors and circuits for high-speed flexible electronics. Nat. Commun. 2014, 5, 5143. [CrossRef] [PubMed]

48. Krasnozhon, D.; Lembke, D.; Nyffeler, C.; Leblebici, Y.; Kis, A. MoS 2 Transistors Operating at Gigahertz Frequencies. Nano Lett. 2014, 14, 5905-5911. [CrossRef] [PubMed]

49. Sanne, A.; Ghosh, R.; Rai, A.; Yogeesh, M.N.; Shin, S.H.; Sharma, A.; Jarvis, K.; Mathew, L.; Rao, R.; Akinwande, D.; et al. Radio Frequency Transistors and Circuits Based on CVD MoS 2 . Nano Lett. 2015, 15, 5039-5045. [CrossRef] [PubMed]

50. Hong, J.; Hu, Z.; Probert, M.; Li, K.; Lv, D.; Yang, X.; Gu, L.; Mao, N.; Feng, Q.; Xie, L.; et al. Exploring atomic defects in molybdenum disulphide monolayers. Nat. Commun. 2015, 6, 6293. [CrossRef] [PubMed]

51. Yu, Z.; Pan, Y.; Shen, Y.; Wang, Z.; Ong, Z.-Y.; Xu, T.; Xin, R.; Pan, L.; Wang, B.; Sun, L.; et al. Towards intrinsic charge transport in monolayer molybdenum disulfide by defect and interface engineering. Nat. Commun. 2014, 5, 5290. [CrossRef] [PubMed]

52. Guo, Y.; Liu, D.; Robertson, J. Chalcogen vacancies in monolayer transition metal dichalcogenides and Fermi level pinning at contacts. Appl. Phys. Lett. 2015, 106, 173106. [CrossRef]

53. Addou, R.; McDonnell, S.; Barrera, D.; Guo, Z.; Azcatl, A.; Wang, J.; Zhu, H.; Hinkle, C.L.; Quevedo-Lopez, M.; Alshareef, H.N.; et al. Impurities and Electronic Property Variations of Natural $\mathrm{MoS}_{2}$ Crystal Surfaces. ACS Nano 2015, 9, 9124-9133. [CrossRef] [PubMed]

54. Das, S.; Chen, H.-Y.; Penumatcha, A.V.; Appenzeller, J. High Performance Multi-layer MoS 2 Transistors with Scandium Contacts. Nano Lett. 2013, 13, 100-105. [CrossRef] [PubMed]

55. Kappera, R.; Voiry, D.; Yalcin, S.E.; Branch, B.; Gupta, G.; Mohite, A.D.; Chhowalla, M. Phase-Engineered Low-Resistance Contacts for Ultrathin $\mathrm{MoS}_{2}$ Transistors. Nat. Mater. 2014, 13, 1128-1134. [CrossRef] [PubMed]

56. Suh, J.; Park, T.-E.; Lin, D.-Y.; Fu, D.; Park, J.; Jung, H.J.; Chen, Y.; Ko, C.; Jang, C.; Sun, Y.; et al. Doping against the Native Propensity of $\mathrm{MoS}_{2}$ : Degenerate Hole Doping by Cation Substitution. Nano Lett. 2014, 14, 6976-6982. [CrossRef] [PubMed]

57. Fang, H.; Tosun, M.; Seol, G.; Chang, T.C.; Takei, K.; Guo, J.; Javey, A. Degenerate n-Doping of Few-Layer Transition Metal Dichalcogenides by Potassium. Nano Lett. 2013, 13, 1991-1995. [CrossRef] [PubMed]

58. Nipane, A.; Karmakar, D.; Kaushik, N.; Karande, S.; Lodha, S. Few-Layer $\mathrm{MoS}_{2}$ p-type Devices Enabled by Selective Doping Using Low Energy Phosphorus Implantation. ACS Nano 2016, 10, 2128-2137. [CrossRef] [PubMed]

59. McDonnell, S.; Addou, R.; Buie, C.; Wallace, R.M.; Hinkle, C.L. Defect-Dominated Doping and Contact Resistance in $\mathrm{MoS}_{2}$. ACS Nano 2014, 8, 2880-2888. [CrossRef] [PubMed]

60. Giannazzo, F.; Fisichella, G.; Piazza, A.; Agnello, S.; Roccaforte, F. Nanoscale inhomogeneity of the Schottky barrier and resistivity in $\mathrm{MoS}_{2}$ multilayers. Phys. Rev. B 2015, 92, 081307. [CrossRef]

61. Giannazzo, F.; Fisichella, G.; Piazza, A.; Di Franco, S.; Greco, G.; Agnello, S.; Roccaforte, F. Impact of Contact Resistance on the Electrical Properties of $\mathrm{MoS}_{2}$ Transistors at Practical Operating Temperatures. Beilstein J. Nanotechnol. 2017, 8, 254-263. [CrossRef] [PubMed]

62. Das, S.; Prakash, A.; Salazar, R.; Appenzeller, J. Toward Low-Power Electronics: Tunneling Phenomena in Transition Metal Dichalcogenides. ACS Nano 2014, 8, 1681-1689. [CrossRef] [PubMed]

63. Giannazzo, F.; Fisichella, G.; Piazza, A.; Di Franco, S.; Greco, G.; Agnello, S.; Roccaforte, F. Effect of Temperature-Bias Annealing on the Hysteresis and Subthreshold Behavior of Multilayer MoS $_{2}$ Transistors. Phys. Status Solidi RRL 2016, 10, 797-801. [CrossRef]

64. Chuang, S.; Battaglia, C.; Azcatl, A.; McDonnell, S.; Kang, J.S.; Yin, X.; Tosun, M.; Kapadia, R.; Fang, H.; Wallace, R.M.; et al. $\mathrm{MoS}_{2}$ P-Type Transistors and Diodes Enabled by High Work Function MoOx Contacts. Nano Lett. 2014, 14, 1337-1342. [CrossRef] [PubMed] 
65. Giannazzo, F.; Fisichella, G.; Greco, G.; Di Franco, S.; Deretzis, I.; La Magna, A.; Bongiorno, C.; Nicotra, G.; Spinella, C.; Scopelliti, M.; et al. Ambipolar $\mathrm{MoS}_{2}$ Transistors by Nanoscale Tailoring of Schottky Barrier Using Oxygen Plasma Functionalization. ACS Appl. Mater. Interfaces 2017, 9, 23164-23174. [CrossRef] [PubMed]

66. Fang, H.; Chuang, S.; Chang, T.C.; Takei, K.; Takahashi, T.; Javey, A. High-Performance Single Layered WSe 2 p-FETs with Chemically Doped Contacts. Nano Lett. 2012, 12, 3788-3792. [CrossRef] [PubMed]

67. Tosun, M.; Chuang, S.; Fang, H.; Sachid, A.B.; Hettick, M.; Lin, Y.; Zeng, Y.; Javey, A. High-Gain Inverters Based on $\mathrm{WSe}_{2}$ Complementary Field-Effect Transistors. ACS Nano 2014, 8, 4948-4953. [CrossRef] [PubMed]

68. Yu, L.; Zubair, A.; Santos, E.J.G.; Zhang, X.; Lin, Y.; Zhang, Y.; Palacios, T. High-Performance WSe ${ }_{2}$ Complementary Metal Oxide Semiconductor Technology and Integrated Circuits. Nano Lett. 2015, 15, 4928-4934. [CrossRef] [PubMed]

69. Roy, T.; Tosun, M.; Kang, J.S.; Sachid, A.B.; Desai, S.B.; Hettick, M.; Hu, C.C.; Javey, A. Field-Effect Transistors Built from All Two-Dimensional Material Components. ACS Nano 2014, 8, 6259-6264. [CrossRef] [PubMed]

70. Esaki, L. New phenomenon in narrow germanium p-n junctions. Phys. Rev. 1958, 109, 603. [CrossRef]

71. Chang, L.L. Resonant tunneling in semiconductor double barriers. Appl. Phys. Lett. 1974, 24, 593. [CrossRef]

72. Agarwal, S.; Yablonovitch, E. Band-Edge Steepness Obtained from Esaki Backward Diode Current-Voltage Characteristics. IEEE Trans. Electron Devices 2014, 61, 1488-1493. [CrossRef]

73. Britnell, L.; Gorbachev, R.V.; Geim, A.K.; Ponomarenko, L.A.; Mishchenko, A.; Greenaway, M.T.; Fromhold, T.M.; Novoselov, K.S.; Eaves, L. Resonant tunnelling and negative differential conductance in graphene transistors. Nat. Commun. 2013, 4, 1794. [PubMed]

74. Mishchenko, A.; Tu, J.S.; Cao, Y.; Gorbachev, R.V.; Wallbank, J.R.; Greenaway, M.T.; Morozov, V.E.; Morozov, S.V.; Zhu, M.J.; Wong, S.L.; et al. Twist-controlled resonant tunnelling in graphene/boron nitride/graphene heterostructures. Nat. Nanotechnol. 2014, 9, 808-813. [PubMed]

75. Kang, S.; Fallahazad, B.; Lee, K.; Movva, H.; Kim, K.; Corbet, C.M.; Taniguchi, T.; Watanabe, K.; Colombo, L.; Register, L.F.; et al. Bilayer Graphene-Hexagonal Boron Nitride Heterostructure Negative Differential Resistance Interlayer Tunnel FET. IEEE Electron Device Lett. 2015, 36, 405-407.

76. Fallahazad, B.; Lee, K.; Kang, S.; Xue, J.; Larentis, S.; Corbet, C.; Kim, K.; Movva, H.C.P.; Taniguchi, T.; Watanabe, K.; et al. Gate-Tunable Resonant Tunneling in Double Bilayer Graphene Heterostructures. Nano Lett. 2015, 15, 428-433. [PubMed]

77. Kang, S.; Prasad, N.; Movva, H.C.P.; Rai, A.; Kim, K.; Mou, X.; Taniguchi, T.; Watanabe, K.; Register, L.F.; Tutuc, E.; et al. Effects of electrode layer band structure on the performance of multilayer graphene-hBN-graphene interlayer tunnel field effect transistors. Nano Lett. 2016, 16, 4975-4981. [PubMed]

78. Burg, G.W.; Prasad, N.; Fallahazad, B.; Valsaraj, A.; Kim, K.; Taniguchi, T.; Watanabe, K.; Wang, Q.; Kim, M.J.; Register, L.F.; et al. Coherent interlayer tunneling and negative differential resistance with high current density in double bilayer graphene-WSe 2 heterostructures. Nano Lett. 2017, 17, 3919-3925. [CrossRef] [PubMed]

79. Campbell, P.M.; Tarasov, A.; Joiner, C.A.; Ready, W.J.; Vogel, E.M. Enhanced Resonant Tunneling in Symmetric 2D Semiconductor Vertical Heterostructure Transistors. ACS Nano 2015, 9, 5000-5008. [PubMed]

80. Srivastava, A.; Fahad, M.S. Vertical $\mathrm{MoS}_{2} / \mathrm{hBN} / \mathrm{MoS}_{2}$ interlayer tunneling field effect transistor. Solid-State Electron. 2016, 126, 96-103.

81. Roy, T.; Tosun, M.; Cao, X.; Fang, H.; Lien, D.-H.; Zhao, P.; Chen, Y.-Z.; Chueh, Y.-L.; Guo, J.; Javey, A. Dual-Gated $\mathrm{MoS}_{2} / \mathrm{WSe}_{2}$ van der Waals Tunnel Diodes and Transistors. ACS Nano 2015, 9, 2071-2079. [PubMed]

82. Nourbakhsh, A.; Zubair, A.; Dresselhaus, M.S.; Palacios, T. Transport properties of a $\mathrm{MoS}_{2} / \mathrm{WSe}_{2}$ heterojunction transistor and its potential for application. Nano Lett. 2016, 16, 1359-1366. [PubMed]

83. Roy, T.; Tosun, M.; Hettick, M.; Ahn, G.H.; Hu, C.; Javey, A. 2D-2D tunneling field-effect transistors using $\mathrm{WSe}_{2} / \mathrm{SnSe}_{2}$ heterostructures. Appl. Phys. Lett. 2016, 108, 83111. [CrossRef]

84. Yan, R.; Fathipour, S.; Han, Y.; Song, B.; Xiao, S.; Li, M.; Ma, N.; Protasenko, V.; Muller, D.A.; Jena, D.; et al. Esaki diodes in van der Waals heterojunctions with broken-gap energy band alignment. Nano Lett. 2015, 15, 5791-5798. [CrossRef] [PubMed]

85. Yu, W.J.; Li, Z.; Zhou, H.; Chen, Y.; Wang, Y.; Huang, Y.; Duan, X. Vertically stacked multi-heterostructures of layered materials for logic transistors and complementary inverters. Nat. Mater. 2013, 12, 246-252. [CrossRef] [PubMed] 
86. Moriya, R.; Yamaguchi, T.; Inoue, Y.; Morikawa, S.; Sata, Y.; Masubuchi, S.; Machida, T. Large current modulation in exfoliated-graphene/ $\mathrm{MoS}_{2} /$ metal vertical heterostructures. Appl. Phys. Lett. 2014, 105, 083119. [CrossRef]

87. Mead, C.A. Operation of Tunnel-Emission Devices. J. Appl. Phys. 1961, 32, 646-652. [CrossRef]

88. Atalla, M.M.; Soshea, R.W. Hot-carrier triodes with thin-film metal base. Solid-State Electron. 1963, 6, $245-250$. [CrossRef]

89. Hensel, J.C.; Levi, A.F.J.; Tung, R.T.; Gibson, J.M. Transistor action in $\mathrm{Si} / \mathrm{CoSi}_{2} / \mathrm{Si}$ heterostructures. Appl. Phys. Lett. 1985, 47, 151-153. [CrossRef]

90. Rosencher, E.; Badoz, P.A.; Pfister, J.C.; Arnaud d'Avitaya, F.; Vincent, G.; Delage, S. Study of ballistic transport in $\mathrm{Si}_{-}-\mathrm{CoSi}_{2}-\mathrm{Si}$ metal base transistors. Appl. Phys. Lett. 1986, 49, 271-273. [CrossRef]

91. Yajima, T.; Hikita, Y.; Hwang, H.Y. A heteroepitaxial perovskite metal-base transistor. Nat. Mater. 2011, 10, 198-201. [CrossRef] [PubMed]

92. Tonouchi, M.; Sakai, H.; Kobayashi, T.; Fujisawa, K. A novel hot-electron transistor employing superconductor base. IEEE Trans. Magn. 1987, 23, 1674-1677. [CrossRef]

93. Heiblum, M.; Thomas, D.C.; Knoedler, C.M.; Nathan, M.I. Tunneling hot-electron transfer amplifier: A hot-electron GaAs device with current gain. Appl. Phys. Lett. 1985, 47, 1105-1107. [CrossRef]

94. Shur, M.S.; Bykhovski, A.D.; Gaska, R.; Asif Khan, M.; Yang, J.W. AlGaN-GaN-AlInGaN induced base transistor. Appl. Phys. Lett. 2000, 76, 3298-3300. [CrossRef]

95. Dasgupta, S.; Raman, N.A.; Speck, J.S.; Mishra, U.K. Experimental demonstration of III-nitride hot-electron transistor with GaN base. IEEE Electron Device Lett. 2011, 32, 1212-1214. [CrossRef]

96. Yang, Z.; Zhang, Y.; Nath, D.N.; Khurgin, J.B.; Rajan, S. Current gain in sub-10nm base GaN tunneling hot electron transistors with AlN emitter barrier. Appl. Phys. Lett. 2015, 106, 032101. [CrossRef]

97. Gupta, G.; Ahmadi, E.; Hestroffer, K.; Acuna, E.; Mishra, U.K. Common Emitter Current Gain $>1$ in III-N Hot Electron Transistors with 7-nm GaN/InGaN Base. IEEE Electron Device Lett. 2015, 36, 439-441. [CrossRef]

98. Kong, B.D.; Jin, Z.; Kim, K.W. Hot-Electron Transistors for Terahertz Operation Based on Two-Dimensional Crystal Heterostructures. Phys. Rev. Appl. 2014, 2, 054006. [CrossRef]

99. Vaziri, S.; Belete, M.; Dentoni Litta, E.; Smith, A.D.; Lupina, G.; Lemme, M.C.; Östlinga, M. Bilayer insulator tunnel barriers for graphene-based vertical hot-electron transistors. Nanoscale 2015, 7, 13096-13104. [CrossRef] [PubMed]

100. Fisichella, G.; Greco, G.; Roccaforte, F.; Giannazzo, F. Current transport in graphene/AlGaN/GaN vertical heterostructures probed at nanoscale. Nanoscale 2014, 6, 8671-8680. [CrossRef] [PubMed]

101. Giannazzo, F.; Fisichella, G.; Greco, G.; Roccaforte, F. Challenges in graphene integration for high-frequency electronics. In AIP Conference Proceedings; AIP Publishing: Melville, NY, USA, 2016; Volume 1749, p. 020004.

102. Giannazzo, F.; Fisichella, G.; Greco, G.; La Magna, A.; Roccaforte, F.; Pecz, B.; Yakimova, R.; Dagher, R.; Michon, A.; Cordier, Y. Graphene integration with nitride semiconductors for high power and high frequency electronics. Phys. Status Solidi A 2017, 214, 1600460. [CrossRef]

103. Zubair, A.; Nourbakhsh, A.; Hong, J.-Y.; Qi, M.; Song, Y.; Jena, D.; Kong, J.; Dresselhaus, M.; Palacios, T. Hot Electron Transistor with van der Waals Base-Collector Heterojunction and High-Performance GaN Emitter. Nano Lett. 2017, 17, 3089-3096. [CrossRef] [PubMed]

104. Kim, K.S.; Zhao, Y.; Jang, H.; Lee, S.Y.; Kim, J.M.; Kim, K.S.; Ahn, J.-H.; Kim, P.; Choi, J.-Y.; Hong, B.H. Large-scale pattern growth of graphene films for stretchable transparent electrodes. Nature 2009, 457, 706-710. [CrossRef] [PubMed]

105. Lupina, G.; Kitzmann, J.; Costina, I.; Lukosius, M.; Wenger, C.; Wolff, A.; Vaziri, S.; Östling, M.; Pasternak, I.; Krajewska, A.; et al. Residual Metallic Contamination of Transferred Chemical Vapor Deposited Graphene. ACS Nano 2015, 9, 4776-4785. [CrossRef] [PubMed]

106. Fisichella, G.; Di Franco, S.; Roccaforte, F.; Ravesi, S.; Giannazzo, F. Microscopic mechanisms of graphene electrolytic delamination from metal substrates. Appl. Phys. Lett. 2014, 104, 233105. [CrossRef]

107. Hong, J.-Y.; Shin, Y.C.; Zubair, A.; Mao, Y.; Palacios, T.; Dresselhaus, M.S.; Kim, S.H.; Kong, J. A Rational Strategy for Graphene Transfer on Substrates with Rough Features. Adv. Mater. 2016, 28, 2382-2392. [CrossRef] [PubMed]

108. Choi, J.-K.; Kwak, J.; Park, S.-D.; Yun, H.D.; Kim, S.-Y.; Jung, M.; Kim, S.Y.; Park, K.; Kang, S.; Kim, S.-D.; et al. Growth of Wrinkle-Free Graphene on Texture-Controlled Platinum Films and Themal-Assisted Transfer of Large-Scale Patterned Graphene. ACS Nano 2015, 9, 679-686. [CrossRef] [PubMed] 
109. Kim, H.H.; Lee, S.K.; Lee, S.G.; Lee, E.; Cho, K. Wetting-Assisted Crack- and Wrinkle-Free Transfer of Wafer-Scale Graphene onto Arbitrary Substrates over a Wide Range of Surface Energies. Adv. Funct. Mater. 2016, 26, 2070-2077. [CrossRef]

110. Giannazzo, F.; Fisichella, G.; Greco, G.; Schilirò, E.; Deretzis, I.; Lo Nigro, R.; La Magna, A.; Roccaforte, F.; Iucolano, F.; Lo Verso, S.; et al. Fabrication and Characterization of Graphene Heterostructures with Nitride Semiconductors for High Frequency Vertical Transistors. Phys. Status Solidi A 2017, 1700653. [CrossRef]

111. Michon, A.; Vézian, S.; Roudon, E.; Lefebvre, D.; Zielinski, M.; Chassagne, T.; Portail, M. Effects of pressure, temperature, and hydrogen during graphene growth on $\mathrm{SiC}$ (0001) using propane-hydrogen chemical vapor deposition. J. Appl. Phys. 2013, 113, 203501. [CrossRef]

112. Bouhafs, C.; Zakharov, A.A.; Ivanov, I.G.; Giannazzo, F.; Eriksson, J.; Stanishev, V.; Kühne, P.; Iakimov, T.; Hofmann, T.; Schubert, M.; et al. Multi-scale investigation of interface properties, stacking order and decoupling of few layer graphene on C-face $4 \mathrm{H}-\mathrm{SiC}$. Carbon 2017, 116, 722-732. [CrossRef]

113. Lee, J.-H.; Lee, E.K.; Joo, W.-J.; Jang, Y.; Kim, B.-S.; Lim, J.Y.; Choi, S.-H.; Ahn, S.J.; Ahn, J.R.; Park, M.-H.; et al. Wafer-Scale Growth of Single-Crystal Monolayer Graphene on Reusable Hydrogen-Terminated Germanium. Science 2014, 344, 286-288. [CrossRef] [PubMed]

114. Varchon, F.; Feng, R.; Hass, J.; Li, X.; Nguyen, B.N.; Naud, C.; Mallet, P.; Veuillen, J.Y.; Berger, C.; Conrad, E.H.; et al. Electronic Structure of Epitaxial Graphene Layers on SiC: Effect of the Substrate. Phys. Rev. Lett. 2007, 99, 126805. [CrossRef] [PubMed]

115. Nicotra, G.; Ramasse, Q.M.; Deretzis, I.; La Magna, A.; Spinella, C.; Giannazzo, F. Delaminated Graphene at Silicon Carbide Facets: Atomic Scale Imaging and Spectroscopy. ACS Nano 2013, 7, 3045-3052. [CrossRef] [PubMed]

116. Giannazzo, F.; Deretzis, I.; La Magna, A.; Roccaforte, F.; Yakimova, R. Electronic transport at monolayer-bilayer junctions in epitaxial graphene on SiC. Phys. Rev. B 2012, 86, 235422. [CrossRef]

117. Sonde, S.; Giannazzo, F.; Raineri, V.; Yakimova, R.; Huntzinger, J.-R.; Tiberj, A.; Camassel, J. Electrical properties of the graphene/4H-SiC (0001) interface probed by scanning current spectroscopy. Phys. Rev. B 2009, 80, 241406. [CrossRef]

118. Speck, F.; Jobst, J.; Fromm, F.; Ostler, M.; Waldmann, D.; Hundhausen, M.; Weber, H.; Seyller, T. The quasi-freestanding nature of graphene on H-saturated SiC (0001). Appl. Phys. Lett. 2011, 99, 122106. [CrossRef]

119. Michon, A.; Tiberj, A.; Vezian, S.; Roudon, E.; Lefebvre, D.; Portail, M.; Zielinski, M.; Chassagne, T.; Camassel, J.; Cordier, Y. Graphene growth on AlN templates on silicon using propane-hydrogen chemical vapor deposition. Appl. Phys. Lett. 2014, 104, 071912. [CrossRef]

120. Dagher, R.; Matta, S.; Parret, R.; Paillet, M.; Jouault, B.; Nguyen, L.; Portail, M.; Zielinski, M.; Chassagne, T.; Tanaka, S.; et al. High temperature annealing and CVD growth of few-layer graphene on bulk AlN and AlN templates. Phys. Status Solidi A 2017, 1600436. [CrossRef]

121. Van der Zande, A.M.; Huang, P.Y.; Chenet, D.A.; Berkelbach, T.C.; You, Y.; Lee, G.-H.; Heinz, T.F.; Reichman, D.R.; Muller, D.A.; Hone, J.C. Grains and grain boundaries in highly crystalline monolayer molybdenum disulphide. Nat. Mater. 2013, 12, 554-561. [CrossRef] [PubMed]

122. Kang, K.; Xie, S.; Huang, L.; Han, Y.; Huang, P.Y.; Mak, K.F.; Kim, C.-J.; Muller, D.; Park, J. High-mobility three-atom-thick semiconducting films with wafer-scale homogeneity. Nature 2015, 520, 656-660. [CrossRef] [PubMed]

123. Dumcenco, D.; Ovchinnikov, D.; Marinov, K.; Lazic, P.; Gibertini, M.; Marzari, N.; Sanchez, O.L.; Kung, Y.-C.; Krasnozhon, D.; Chen, M.-W.; et al. Large-Area Epitaxial Monolayer MoS 2 . ACS Nano 2015, 9, 4611-4620. [CrossRef] [PubMed]

124. Ruzmetov, D.; Zhang, K.; Stan, G.; Kalanyan, B.; Bhimanapati, G.R.; Eichfeld, S.M.; Burke, R.A.; Shah, P.B.; O'Regan, T.P.; Crowne, F.J.; et al. Vertical 2D/3D Semiconductor Heterostructures Based on Epitaxial Molybdenum Disulfide and Gallium Nitride. ACS Nano 2016, 10, 3580-3588. [CrossRef] [PubMed]

125. Vervuurt, R.H.J.; Kessels, W.M.M.; Bol, A.A. Atomic Layer Deposition for Graphene Device Integration. Adv. Mater. Interfaces 2017, 1700232. [CrossRef]

126. Kim, S.; Nah, J.; Jo, I.; Shahrjerdi, D.; Colombo, L.; Yao, Z.; Tutuc, E.; Banerjee, S.K. Realization of a High Mobility Dual-Gated Graphene Field-Effect Transistor with $\mathrm{Al}_{2} \mathrm{O}_{3}$ Dielectric. Appl. Phys. Lett. 2009, 94, 062107. [CrossRef] 
127. Jandhyala, S.; Mordi, G.; Lee, B.; Lee, G.; Floresca, C.; Cha, P.-R.; Ahn, J.; Wallace, R.M.; Chabal, Y.J.; Kim, M.J.; et al. Atomic Layer Deposition of Dielectrics on Graphene Using Reversibly Physisorbed Ozone. ACS Nano 2012, 6, 2722-2730. [CrossRef] [PubMed]

128. Fisichella, G.; Schilirò, E.; Di Franco, S.; Fiorenza, P.; Lo Nigro, R.; Roccaforte, F.; Ravesi, S.; Giannazzo, F. Interface Electrical Properties of $\mathrm{Al}_{2} \mathrm{O}_{3}$ Thin Films on Graphene Obtained by Atomic Layer Deposition with an in Situ Seedlike Layer. ACS Appl. Mater. Interfaces 2017, 9, 7761-7771. [CrossRef] [PubMed]

129. Ismach, A.; Chou, H.; Ferrer, D.A.; Wu, Y.; McDonnell, S.; Floresca, H.C.; Covacevich, A.; Pope, C.; Piner, R.; Kim, M.J.; et al. Toward the controlled synthesis of hexagonal boron nitride films. ACS Nano 2012, 6, 6378-6385. [CrossRef] [PubMed]

130. Tay, R.Y.; Griep, M.H.; Mallick, G.; Tsang, S.H.; Singh, R.S.; Tumlin, T.; Teo, E.H.T.; Karna, S.P. Growth of large single-crystalline two-dimensional boron nitride hexagons on electropolished copper. Nano Lett. 2014, 14, 839-846. [CrossRef] [PubMed]

131. Lu, G.; Wu, T.; Yuan, Q.; Wang, H.; Wang, H.; Ding, F.; Xie, X.; Jiang, M. Synthesis of large single-crystal hexagonal boron nitride grains on $\mathrm{Cu}-\mathrm{Ni}$ alloy. Nat. Commun. 2015, 6, 6160. [CrossRef] [PubMed]

132. Sonde, S.; Dolocan, A.; Lu, N.; Corbet, C.; Kim, J.; Tutuc, E.; Banerjee, S.K.; Colombo, L. Ultrathin wafer-scale hexagonal boron nitride on dielectric surfaces by diffusion and segregation mechanism. 2D Mater. 2017, 4, 025052. [CrossRef]

133. Yang, W.; Chen, G.; Shi, Z.; Liu, C.-C.; Zhang, L.; Xie, G.; Cheng, M.; Wang, D.; Yang, R.; Shi, D.; et al. Epitaxial growth of single-domain graphene on hexagonal boron nitride. Nat. Mater. 2013, 12, $792-797$. [CrossRef] [PubMed]

134. Shi, Y.; Zhou, W.; Lu, A.-Y.; Fang, W.; Lee, Y.-H.; Hsu, A.L.; Kim, S.M.; Kim, K.K.; Yang, H.Y.; Li, L.-J.; et al. van der Waals Epitaxy of $\mathrm{MoS}_{2}$ Layers Using Graphene as Growth Templates. Nano Lett. 2012, 12, 2784-2791. [CrossRef] [PubMed]

135. Lin, Y.-C.; Lu, N.; Perea-Lopez, N.; Li, J.; Lin, Z.; Peng, X.; Lee, C.H.; Sun, C.; Calderin, L.; Browning, P.N.; et al. Direct Synthesis of van der Waals Solids. ACS Nano 2014, 8, 3715-3723. [CrossRef] [PubMed]

(C) 2018 by the authors. Licensee MDPI, Basel, Switzerland. This article is an open access article distributed under the terms and conditions of the Creative Commons Attribution (CC BY) license (http:/ / creativecommons.org/licenses/by/4.0/). 